Manuscript Number: UCLIM-D-16-00066R2

Title: Urban wind fields: phenomena in transformation

Article Type: Research Paper

Keywords: urban wind fields; wind directions; wind speeds; urban morphology; meteorological station

Corresponding Author: Dr. Sergey V. Mikhailuta, Ph.D.

Corresponding Author's Institution: Krasnoyrask Regional Center of Standardization and Metrology

First Author: Sergey V. Mikhailuta, Ph.D.

Order of Authors: Sergey V. Mikhailuta, Ph.D.; Anatoly A. Lezhenin, Ph.D.; Anne Pitt; Olga V. Taseiko, Ph.D.

Abstract: This article shows how undisturbed wind streams undergo complex transformations in speed and directions as they interact with different areas in Krasnoyarsk City. Fifteen years of data from urban monitoring stations were collected, averaged and analyzed, and these data show how buildings' layout determines the number of possible wind speeds and directions at specific monitoring points.

Wind speeds at some monitoring stations can increase up to 40\% as compared to the undisturbed wind flow speed at the meteorological station. But some urban points have 300\% more calm periods than at the station outside the city.

This paper shows the complete transformation of the undisturbed wind flow caused by non-uniform relief and building arrangements. These results can be used to verify numerical simulation models of air pollution dispersion and to use this information to better parametrize a wide range of problems of wind flows in urban areas.

Suggested Reviewers:

Opposed Reviewers:

Response to Reviewers: Dear Editor, First, we would like to thank reviewer \#2 for his detailed comments, and then we would like to present our response to these comments.

Reviewer comment Nol: The needs and gaps in the field should have been explicitly defined at the end of the brief literature review. In addition, it should have been clarified how this study is going to fill those gaps.

Response to Reviewer comment No. 1: We have added the following sentences to respond to these points.

To solve the problems of managing air quality and regulating industrial emissions in cities, data from the nearest meteorological stations are used, even though these data don't necessarily represent real wind fields 
accurately. Using these data in the standard methods for calculating air pollution fields, for example OND-86 (OND-86, 1987), can lead to

erroneous conclusions. In this regard, the necessary characteristics of wind speed and direction in urban areas should be averaged over various meteorological conditions. That, in turn, requires long-term (not less than 5 years') observations from meteorological stations in different urban areas.

Reviewer comment No2: The studied case described in section 2 should have been justified.

Response to Reviewer comment No. 2: We have added the following sentences to respond to these points.

This data reflects the wind mode in the study area from 1995 to 2010, and it includes the entire range of meteorological conditions.

The wind flow distributions at the Krasnoyarsk meteorological station (WMO index \#29570) agree with the results taken over the last 100 years (Klimat Krasnoyarska, 1982).

Reviewer comment No3: In section 4, the results are described, however, more justification should have been provided to explain the results. For example, the wind speed at point 8 is higher the wind speed at

meteorological station. This should have been justified and also similar cases in the open literature should have been address to support the rationale behind this behavior.

Response to Reviewer comment No. 3: We have added the following sentences to respond to these points.

The differences in wind speeds at different monitoring stations can be connected to the orientation of elements of urban development (Beller, 2011; Kim, 2014).

Reviewer comment No 4: It is highly recommended to represent the figures 5, 7, 9, 11, 13, 15 and 17 using Boxplot to show the average and median as well at outliers for each month.

Response to Reviewer comment No. 4: The figures 5, 7, 9, 11, 13, 15 and 17 represented using Boxplot to show the average and median as well at outliers for each month. 


\section{Dear Editor,}

First, we would like to thank reviewer \#2 for his detailed comments, and then we would like to present our response to these comments.

\begin{tabular}{|c|c|c|}
\hline \# & Reviewer comment & Answer \\
\hline 1 & $\begin{array}{l}\text { The needs and gaps in the field should } \\
\text { have been explicitly defined at the end of } \\
\text { the brief literature review. In addition, it } \\
\text { should have been clarified how this study } \\
\text { is going to fill those gaps. }\end{array}$ & $\begin{array}{l}\text { We have added the following sentences to respond to these points. } \\
\text { To solve the problems of managing air quality and regulating } \\
\text { industrial emissions in cities, data from the nearest meteorological } \\
\text { stations are used, even though these data don't necessarily represent } \\
\text { real wind fields accurately. Using these data in the standard methods } \\
\text { for calculating air pollution fields, for example OND-86 (OND-86, } \\
\text { 1987), can lead to erroneous conclusions. In this regard, the necessary } \\
\text { characteristics of wind speed and direction in urban areas should be } \\
\text { averaged over various meteorological conditions. That, in turn, requires } \\
\text { long-term (not less than } 5 \text { years') observations from meteorological } \\
\text { stations in different urban areas. }\end{array}$ \\
\hline 2 & $\begin{array}{l}\text { The studied case described in section } 2 \\
\text { should have been justified. }\end{array}$ & $\begin{array}{l}\text { We have added the following sentences to respond to these points. } \\
\text { This data reflects the wind mode in the study area from } 1995 \\
\text { to 2010, and it includes the entire range of meteorological conditions. } \\
\text { The wind flow distributions at the Krasnoyarsk meteorological } \\
\text { station (WMO index \#29570) agree with the results taken over the last } \\
100 \text { years (Klimat Krasnoyarska, 1982). }\end{array}$ \\
\hline 3 & $\begin{array}{l}\text { In section } 4 \text {, the results are described, } \\
\text { however, more justification should have } \\
\text { been provided to explain the results. For } \\
\text { example, the wind speed at point } 8 \text { is } \\
\text { higher the wind speed at meteorological } \\
\text { station. This should have been justified } \\
\text { and also similar cases in the open } \\
\text { literature should have been address to } \\
\text { support the rationale behind this behavior. }\end{array}$ & $\begin{array}{l}\text { We have added the following sentences to respond to these points. } \\
\text { The differences in wind speeds at different monitoring } \\
\text { stations can be connected to the orientation of elements of urban } \\
\text { development (Beller, 2011; Kim, 2014). }\end{array}$ \\
\hline 4 & $\begin{array}{l}\text { It is highly recommended to represent the } \\
\text { figures } 5,7,9,11,13,15 \text { and } 17 \text { using } \\
\text { Boxplot to show the average and median } \\
\text { as well at outliers for each month. }\end{array}$ & $\begin{array}{l}\text { The figures } 5,7,9,11,13,15 \text { and } 17 \text { represented using Boxplot to } \\
\text { show the average and median as well at outliers for each month. }\end{array}$ \\
\hline
\end{tabular}




\title{
Urban wind fields: phenomena in transformation
}

\author{
Sergey V. Mikhailuta, Anatoly A. Lezhenin, Anne Pitt, Olga V. Taseiko
}

Abstract

This article shows how undisturbed wind streams undergo complex transformations in speed and directions as they interact with different areas in Krasnoyarsk City. Fifteen years of data from urban monitoring stations were collected, averaged and analyzed, and these data show how buildings' layout determines the number of possible wind speeds and directions at specific monitoring points.

Wind speeds at some monitoring stations can increase up to $40 \%$ as compared to the undisturbed wind flow speed at the meteorological station. But some urban points have $300 \%$ more calm periods than at the station outside the city.

This paper shows the complete transformation of the undisturbed wind flow caused by nonuniform relief and building arrangements. These results can be use to verify numerical simulation models of air pollution dispersion and to use this information to better parametrize a wide range of problems of wind flows in urban areas.

Keywords: urban wind fields, wind directions, wind speeds, urban morphology, meteorological station, observations

Sergey V. Mikhailuta: Ph.D., Environment Expert of the Krasnoyarsk State Regional Center of Standardization, Metrology and Testing, Academician Vavilov St., 1A, Krasnoyarsk, Krasnoyarsk region, 660093;

Senior researcher of the Siberian Federal University, 79 Svobodny pr., 660041 Krasnoyarsk, Russia, http://www.sfu-kras.ru, Mob.: +7-923-280-47-80, e-mail: mikhailuta@gmail.com

Anatoly A. Lezhenin: Ph.D., Senior researcher of the Laboratory of the Mathematical Modeling of the Processes in the Atmosphere and Hydrosphere, Institute of Computational Mathematics and Mathematical Geophysics (former Computing Center), Siberian Branch of the Russian Academy of Sciences, 6, ave. Ac. Lavrentieva, Novosibirsk, 630090, Russia, Tel. Office: +7(383) 330-64-50 Mob.: +7-905-950-99-10 Fax: +7(383) 330-87-83 http://www.sscc.ru http://icmmg.nsc.ru/ru e-mail: lezhenin@ommfao.sscc.ru

Anne Pitt: Researcher of the International Center for Organism Extreme State Research, Krasnoyarsk scientific center, Siberian Branch of the Russian Academy of Sciences, Academgorodok, 50 - 12/2, Krasnoyarsk, 660036, Russia, Tel. Office: +7 (908) 208-24-36, e-mail: thewhitecat3@gmail.com

Olga V. Taseiko: Ph.D., Associate professor of the Siberian State Aerospace University, Office A-406, 31, Krasnoyarsky Rabochy Av., 660014 Krasnoyarsk, Russia Tel.: +7 (391) 262-95-53, +7 (391) 291-90-63, +7 (391) 291-90-64, +7 (391) 262-93-62 Fax: +7 (391) 291-90-63 E-mail: ums@sibsau.ru Web-site: www.ums.sibsau.ru, taseiko@gmail.com; Associate professor of the Siberian Federal University, 79 Svobodny pr., 660041 Krasnoyarsk, Russia 
- The number of possible wind directions at a concrete point is determined by the urban morphology.

- The distinctive feature of wind streams in the built-up areas is that they correlate to various extents with the external winds speed.

- Wind directions and speeds and the morphological features of the built-up areas shows the effects of splitting wind flows at specific buildings and their distortions on the edges of buildings, and the impact of permeability in built-up areas.

- The winds in the built-up area are characterized by steady directional flows that are not representative of the patterns recorded at the external meteorological station. 


\title{
Urban wind fields: phenomena in transformation
}

\begin{abstract}
This article shows how undisturbed wind streams undergo complex transformations in speed and direction as they interact with different features in various areas of Krasnoyarsk City. Fifteen years of data from urban monitoring stations were collected, averaged and analyzed, and these data show how buildings' layout determines the number of possible wind speeds and directions at specific monitoring points.

Wind speeds at some monitoring stations can increase up to $40 \%$ as compared to the undisturbed wind flow speed at the meteorological station. But some urban points have $300 \%$ more calm periods than at the station outside the city.

This paper shows the complete transformation of the undisturbed wind flow caused by nonuniform relief and building arrangements. These results can be used to verify numerical simulation models of air pollution dispersion and to use this information to better parametrize a wide range of problems of wind flows in urban areas.
\end{abstract}

Keywords: urban wind fields, wind directions, wind speeds, urban morphology, meteorological station, observations

\section{Introduction}

Many scientific works explore the different characteristics of urban wind fields (Simiu and Scanlan, 1996; Plate, 1999; Gadian et al., 2004; Raputa et al., 2011; Bady et al., 2011; Lo Brano et al., 2011). These works investigate how best to describe wind streams in urban areas, to identify sources of urban air pollution, to predict extreme meteorological conditions (sharp increases or decreases of urban wind speeds), or to plan the safe development of urban areas.

Research on how urbanization modifies wind fields is conducted through three different approaches. The first is natural (field) observation (measurements), using ultrasonic anemometers and other meteorological equipment (Gadian et al., 2004; Lo Brano et al., 2011), the second is the mathematical (hydrodynamic) modeling of processes in the atmosphere (Jacobson, 2005; Nowak et al., 2006; Raputa et al., 2011), and the third, and less common, is using physical models in wind tunnels (Plate, 1999; Bady et al., 2011).

These three areas of study are all united by a single problem - the search for an appropriate parametrization to accurately describe the observed transformations, namely the characteristics of wind streams changed as a result of urban building and other factors.

This article shows the great variety of wind stream transformations which are caused by buildings of different parameters, such as height and density, in urban areas, using data collected over 15 years in Krasnoyarsk City, Siberia.

The interaction between an undisturbed wind flow and building settlements determines urban wind patterns (Gao et. al., 2012). Within an urban canopy (defined here as the space below roof level around buildings), the formation of an urban wind environment is important for human health, indoor and outdoor thermal comfort, air quality and the energy performance of buildings (Priyadarsini et al., 2008; Memon et al., 2010; Yang and Yuguo, 2011). For example, the cooling effect of urban wind, especially at night, helps to mitigate the adverse effects of an urban heat island on human thermal comfort both indoors and outdoors. Also, a favorable urban wind pattern indirectly contributes to the reduction of carbon dioxide emissions as passive, natural indoor ventilation reduces the need for mechanical air conditioning (Kolokotroni et. al., 2006; Fung et al., 
2006). Moreover, air pollution in an urban environment is most effectively dissipated by the appropriate distribution of wind-induced airflows (Shilton et al., 2002; Kato et al., 2009; Claus et al., 2012; Branis et al., 2014).

Currently, there is no comprehensive, accurate representation of the multiple factors influencing urban wind flows. Wind tunnel experiments do not completely show real physical processes, and mathematical modelling presents a simplified version of these processes. Therefore, only in-situ observations and measurements can give researchers the data they need to understand the transformations of urban wind flows. However, the detailed monitoring of an entire city requires complete, accurate measurements taken over many years, which is expensive. Actual urban monitoring is usually done for quite limited areas and periods of time. This paper shows unique data of the stable patterns of wind flow transformation in Krasnoyarsk City over 15 years. We present a phenomenological analysis of the influences of urban morphology and calculate the real numerical parameters characterizing the features of wind flow transformation. These results improve the understanding of the processes of urban wind flow transformation which can be used for many purposes, including city planning and management.

To solve the problems of managing air quality and regulating industrial emissions in cities, data from the nearest meteorological stations are used, even though these data don't necessarily represent real wind fields accurately. Using these data in the standard methods for calculating air pollution fields, for example OND-86 (OND-86, 1987), can lead to erroneous conclusions. In this regard, the necessary characteristics of wind speed and direction in urban areas should be averaged over various meteorological conditions. That, in turn, requires long-term (not less than 5 years) observations from meteorological stations in different urban areas.

\section{Objective}

This article's objective is to present 15 years of research that show the characteristics and properties of changed wind streams at specific points in Krasnoyarsk City (Fig. 1).

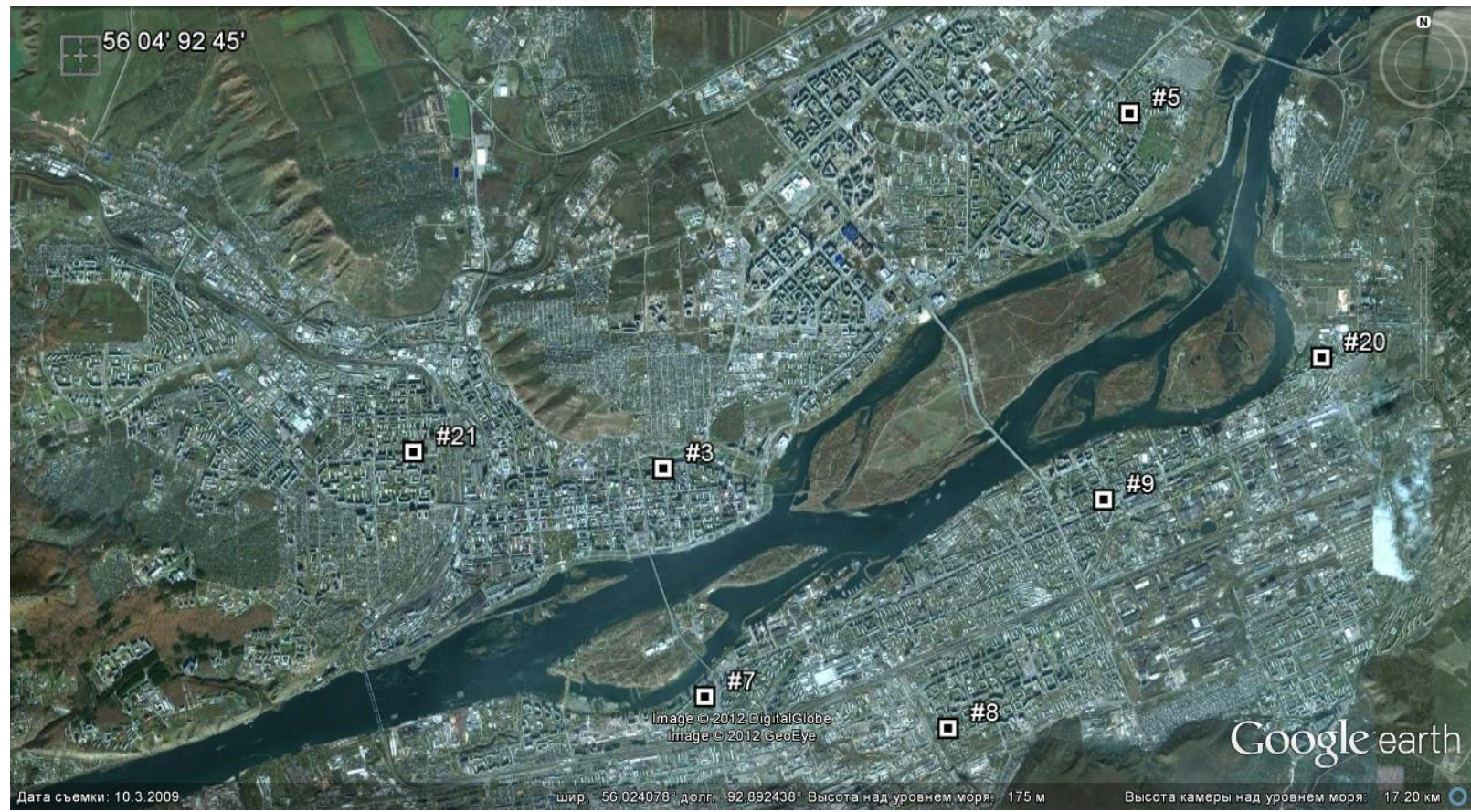

Fig. 1. At the top left corner is the Krasnoyarsk meteorological station (Index WMO 29570) and the numbered points are the city weather and air pollution monitoring stations in Krasnoyarsk City. 
This article describes changes in wind directions and speeds as a result of interactions between the natural undisturbed wind flow and the urban environment and building configurations of Krasnoyarsk City. For this purpose, we:

1. investigate the distribution of wind directions and speeds at the Krasnoyarsk meteorological station (index WMO 29570) from 1995 to 2010;

2. examine local morphological features of urban building in specified areas;

3. construct a wind-rose (frequency of winds) at each specified point and examine its transformation by comparing it with the initial wind flow; and

4. describe and analyze changes and modifications in air flows.

The wind direction and velocity are measured at approximately $10 \mathrm{~m}$ at all monitoring stations.

We consider 15 years of data, during which period the city developed rapidly. More recent changes of wind streams, due to constructions built since 2010, will be studied in future articles.

This data reflects the wind mode in the study area from 1995 to 2010, and it includes the entire range of meteorological conditions. 


\section{Methods}

Data from the Krasnoyarsk meteorological station (WMO index \#29570) from 1995 to 2010 (Weather archive) provided the background wind flow.

To analyze wind streams at specified points in Krasnoyarsk City, data from the Krasnoyarsk Center for Hydrometeorology and Air Pollution Monitoring from 1995-2010 were used.

The meteorological software WRPlot (WRPLOT View, Version 7.0.0) analyzed the distributions of wind directions and speeds.

\section{Results and Discussion}

\subsection{Krasnoyarsk meteorological station}

The Krasnoyarsk meteorological station had homogeneous wind streams during the entire period considered (Fig. 2).

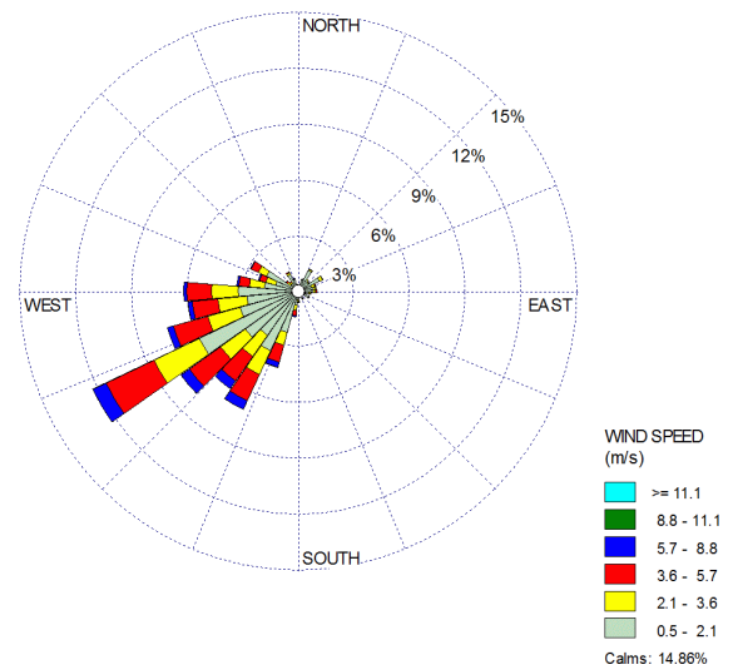

Fig. 2. Frequency of wind directions at the Krasnoyarsk meteorological station (from 1995 to 2010).

Figure 2 shows that winds from the southwest are most common, at approximately $38 \%$ of the total. Winds from the west are $17 \%$ wind speed up to $5 \mathrm{~m} / \mathrm{s}$. North, northwest and northeast winds are weak with wind speeds of less than $2 \mathrm{~m} / \mathrm{s}$.

This information is most often used for planning construction and situating objects (including industrial) in the city and its vicinities.

The wind flow distributions at the Krasnoyarsk meteorological station (WMO index \#29570) agree with the results taken over the last 100 years (Klimat Krasnoyarska, 1982).

\subsection{Features of wind directions and speeds in built-up areas}

When an undisturbed, incoming wind stream meets a built-up environment, its speed and direction change (Fig. 3). 
NoRTH

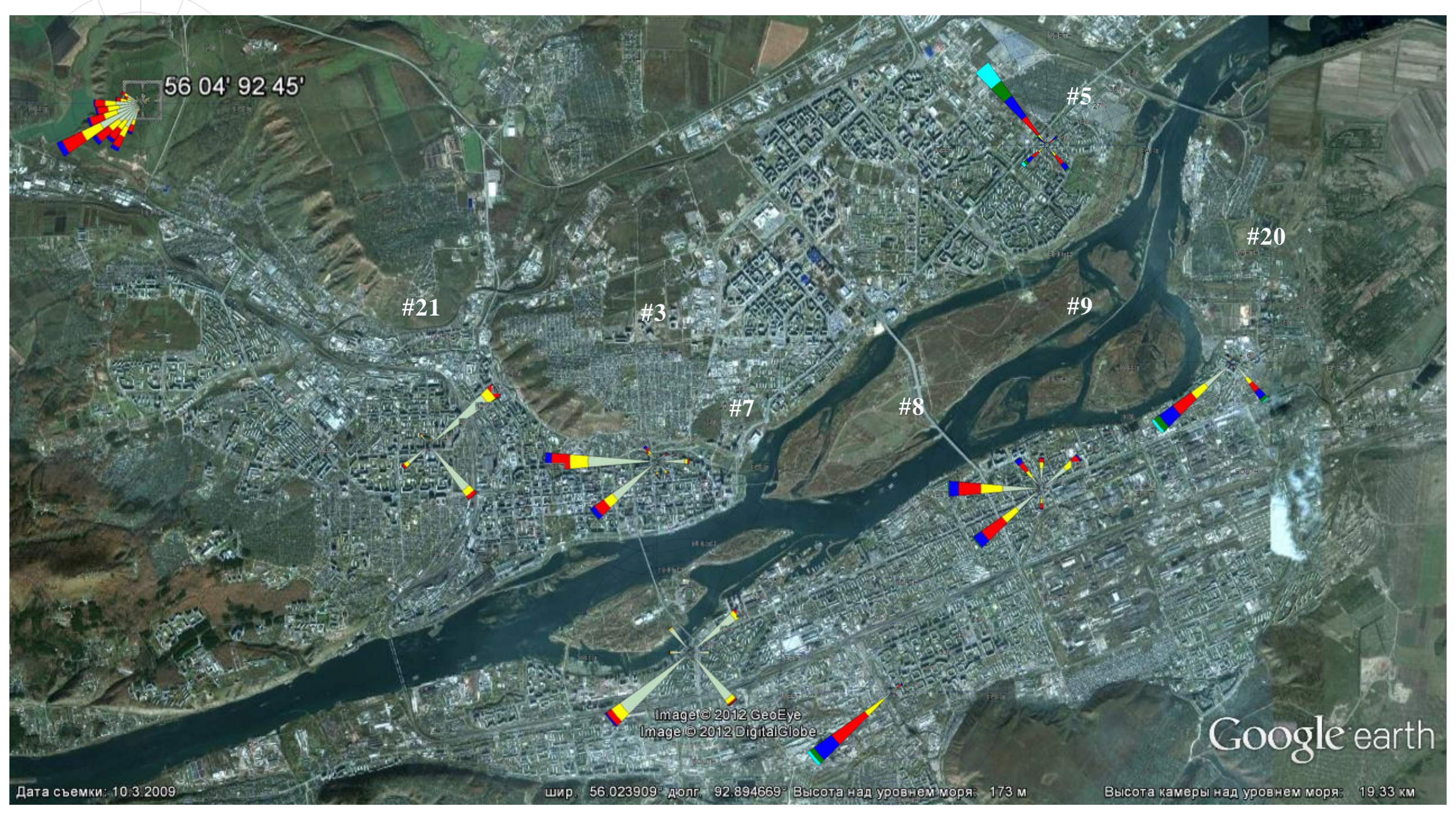

Fig. 3. The directions of winds at the meteorological station and in urban areas of Krasnoyarsk (data from 1995-2010 are averaged). 
Figure 3 shows that when the meteorological station has prevailing wind from sector $180^{\circ}$ $270^{\circ}$, point \#21 has two prevailing (directions with highest probability) sectors for wind streams: $45^{\circ}-55^{\circ}$ (north-east direction - opposite to the winds' direction at the meteorological station) and $135^{\circ}-145^{\circ}$ (south-east direction).

Point \#3 has prevailing winds from the west and south-west for all years, while the winds at point \#5 are mainly from the north-west.

On Krasnoyarsk's right bank, all observation points have wind directions that are different from those at the meteorological station. Generally, these wind streams are characterized by a great number of narrow (about $10^{\circ}$ ) sectors. For example, observation point $\# 8$ has prevailing winds from the south-west $\left(225^{\circ}-235^{\circ}\right.$ sector). Winds from any other direction to this point are rare.

Seasonal and monthly analyses of wind direction variations at the Krasnoyarsk meteorological station for the 1995-2010 period show that the wind directions at observation points in urbanized areas (Fig. 3) are stable.

The observed transformations in wind directions are connected to features of local urban morphology (Fig. 4).

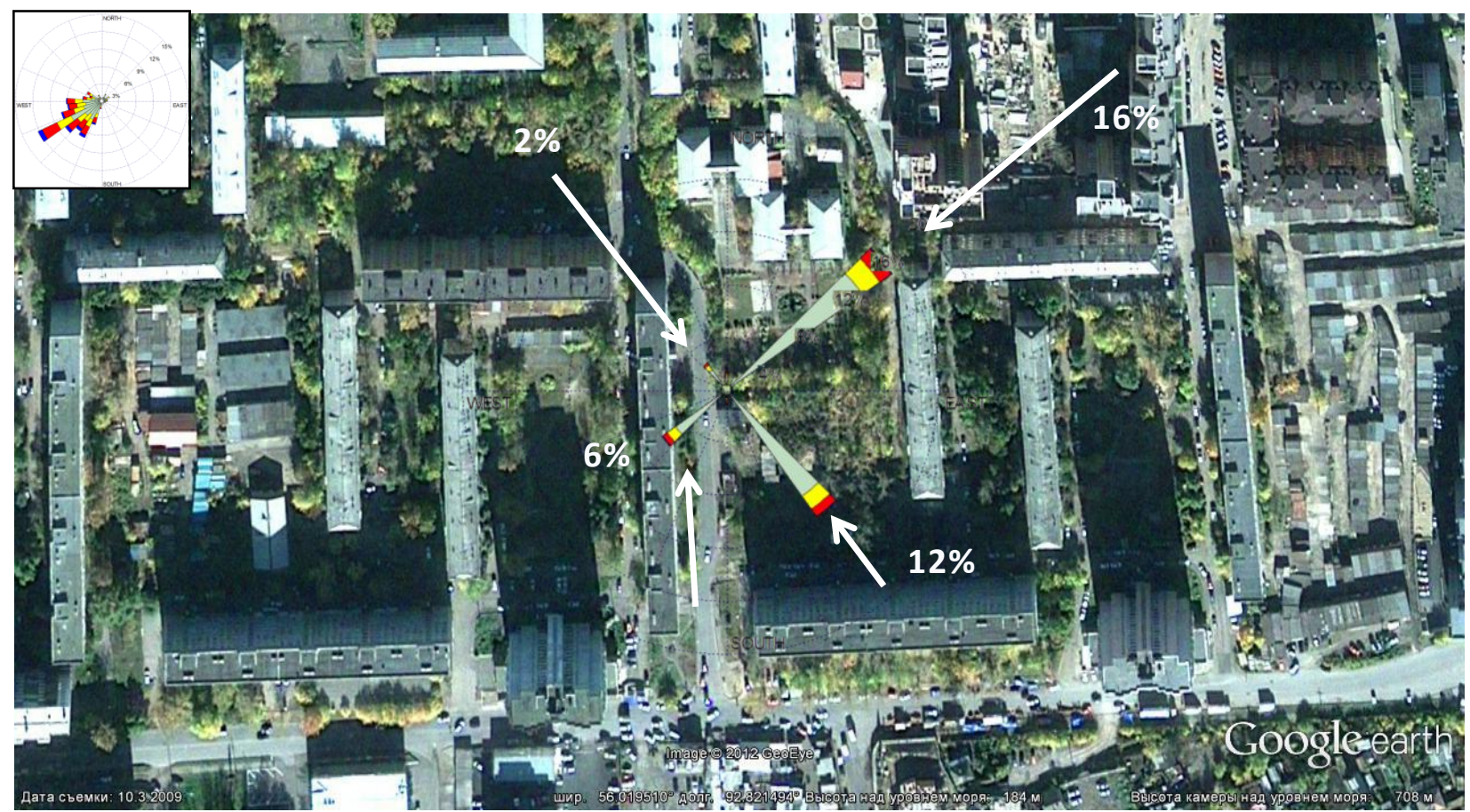

Fig. 4. Wind directions at point \#21 (frequencies are shown in percentages). In the top left corner is the windrose for the meteorological station. The percentage of calm at point \#21 is greater than $60 \%$.

It is possible to see (Fig. 4) that the arrangement of tall buildings situated around point \#21 produces very specific wind modes of four wind directions, and only two of these are prevalent. The prevailing streams have directions of $45^{\circ}$ (north) and $135^{\circ}$ (southeast), and these are uncommon for the meteorological station which has prevailing southwest winds. But the wind speed usually does not exceed $1 \mathrm{~m} / \mathrm{s}$ at this point.

In Fig. 5 the average monthly wind speeds at point \#21 and the Krasnoyarsk meteorological station are shown. 


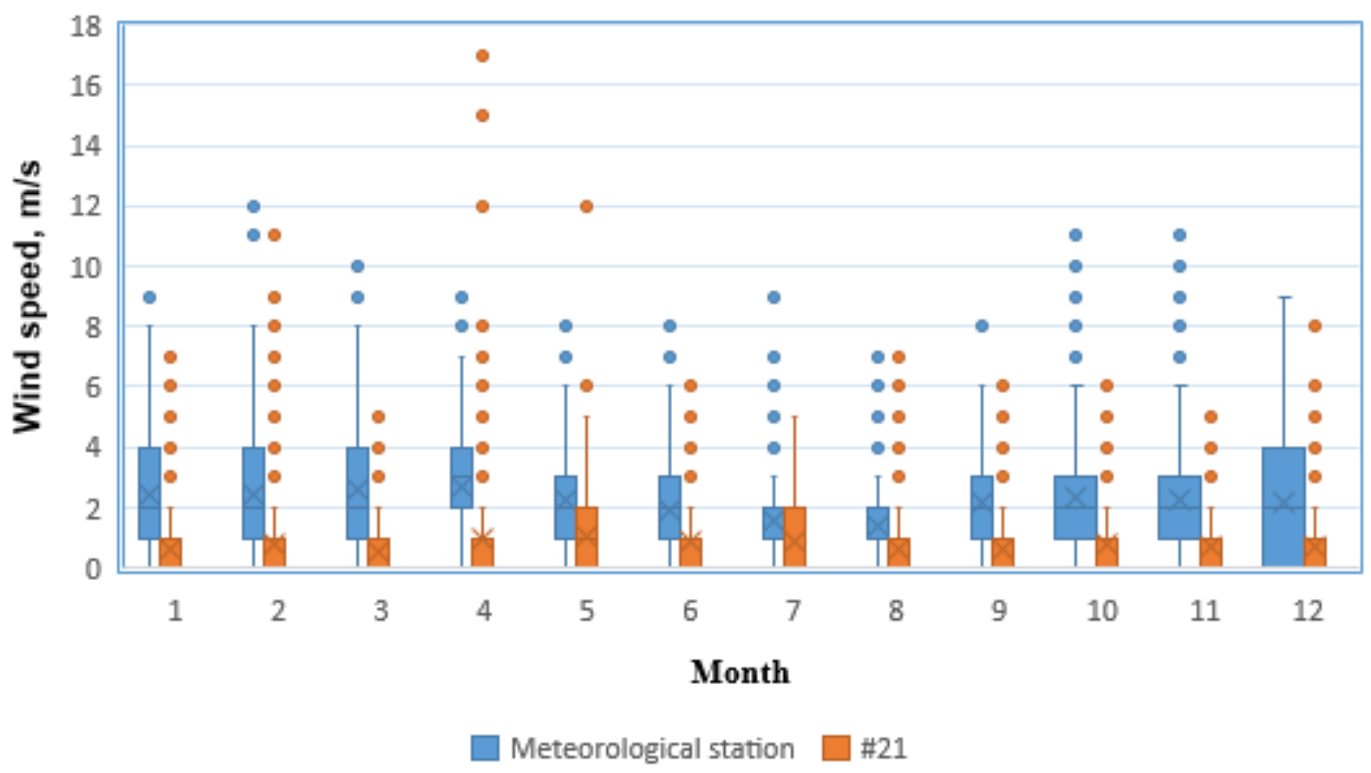

Fig. 5. Average (during 1995-2010) of monthly wind speeds at point \#21 and at the Krasnoyarsk meteorological station.

The average wind speed at point \#21, in a built-up area of the city, changes slightly over the course of a year, varying from $0.5-1.0 \mathrm{~m} / \mathrm{s}$, while at the Krasnoyarsk meteorological station the average wind speed ranges more significantly, from 1.5 to $2.7 \mathrm{~m} / \mathrm{s}$, at different months. Figure 5 shows that changes of wind speed at this point are poorly correlated to changes of wind speed at the Krasnoyarsk meteorological station (correlation coefficient 0.01). This means that the undisturbed wind flow and the wind characteristics at point \#21 cannot be attributed to the high building density of about $20 \%$.

In Figure 6 the wind directions at point \#3, located in downtown Krasnoyarsk, are given. 


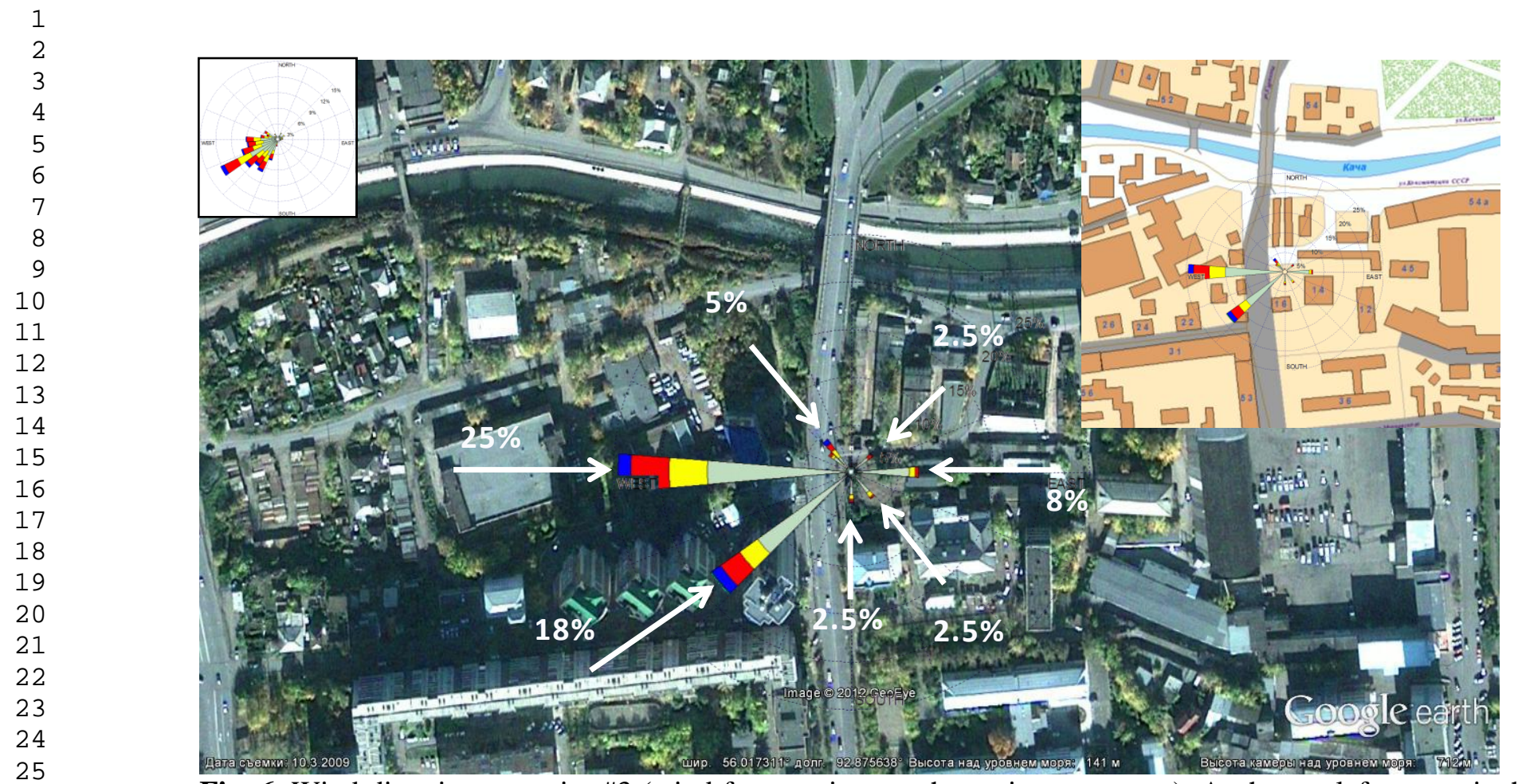

Fig. 6. Wind directions at point \#3 (wind frequencies are shown in percentage). At the top left corner is the wind rose for the Krasnoyarsk meteorological station. The frequency of calm at point \#3 is about $30 \%$.

At point \#3 seven wind directions occur, but only two have significant frequencies, the west (25\%) and southwest (18\%) directions. In this case it is clearly seen (Fig. 6) that these two directions are generated by a wind stream splitting through the $15 \mathrm{~m}$ high buildings located in the southwest sector.

Even though the building density is high in this district (20\%), point \#3 is characterized by a high coefficient of correlation (0.72) with the wind speeds at the meteorological station. A reduction of approximately $1 \mathrm{~m} / \mathrm{s}$ wind speed occurs.

The variations of yearly wind speeds at point \#3, point \#21 and the Krasnoyarsk meteorological station are presented in Figure 7. 
Fig. 7. Monthly averages (during 1995-2010) of yearly wind speeds at points \#3, \#21 and the meteorological station.

Figure 8 shows the frequency of winds at point \#5, which is located near the Krasnoyarsk Aluminum Smelter. The wind stream through city buildings at this point shows that a north-west wind direction prevails here throughout the year, although this direction is unusual for the meteorological station. The wind speed at point \#5 increases in comparison with the wind speed at the station.

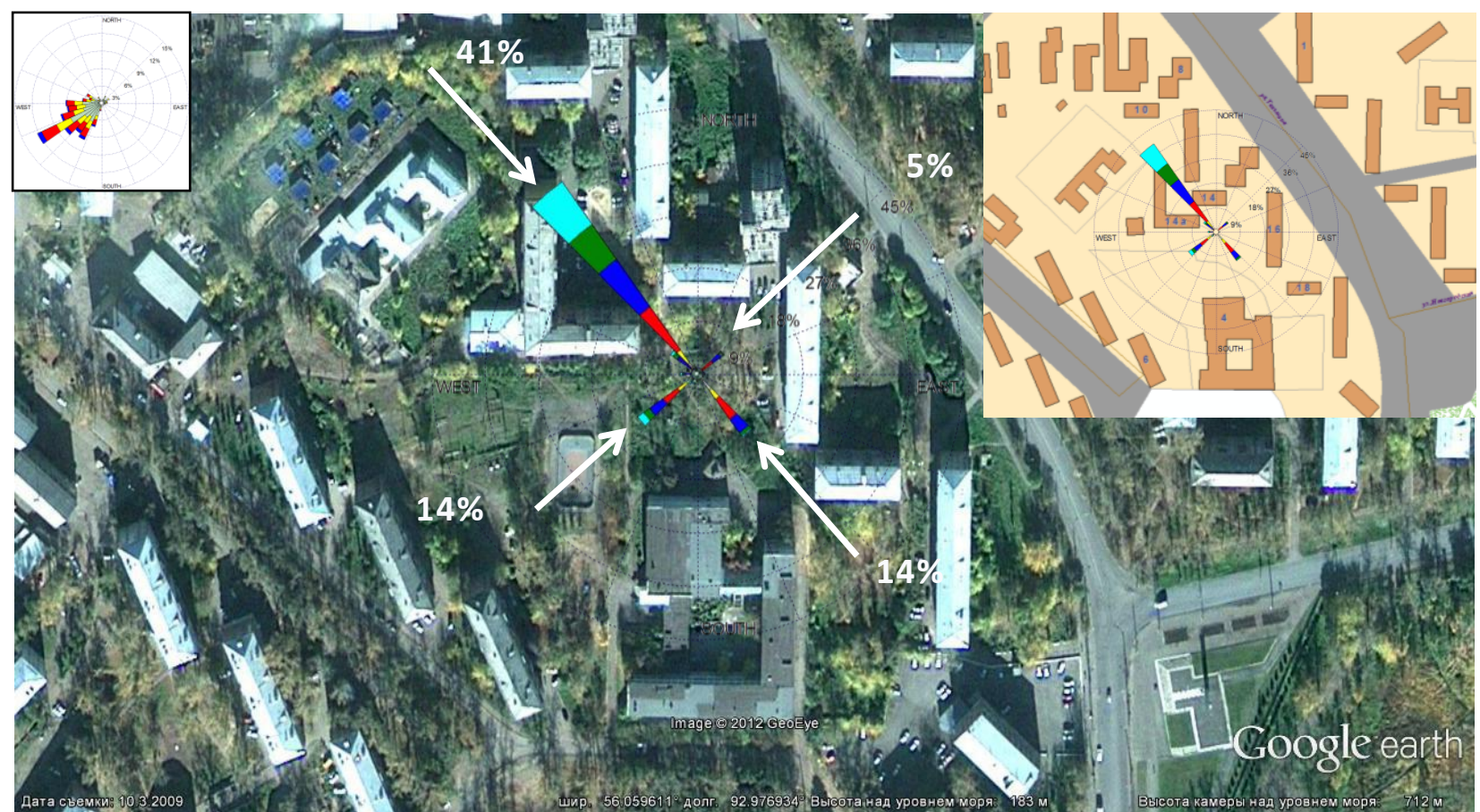

Fig. 8. Wind directions at point \#5 (wind frequencies are shown in percentages). The wind- rose for the meteorological station is shown in the top left corner. The frequency of calm at point \#5 is about $18 \%$. 
The frequency of winds from the northwest direction at the Krasnoyarsk meteorological station is less than 3\% (Fig. 2), while at point \#5, in an urban district, this direction is the most common (the frequency of winds from this direction is greater than 40\%). This can be explained by the presence of tall buildings (about $30 \mathrm{~m}$ ) located across a wind stream from a meteorological station.

Another phenomenon of wind pattern transformation at point \#5 is the increase in wind speed (Fig. 9).

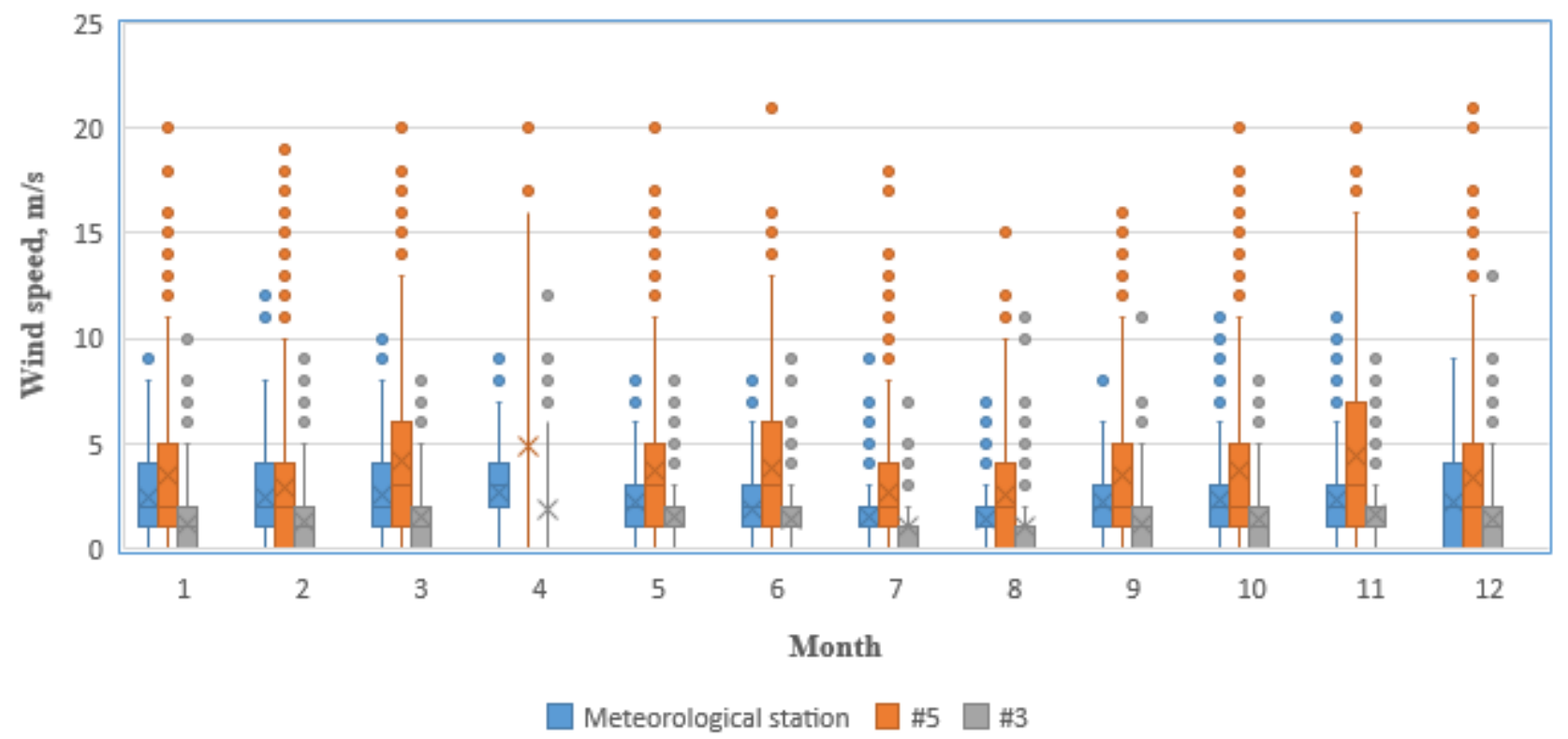

Fig. 9. Yearly averages (during 1995-2010) of monthly wind speeds at points \#3, \#5 and the Krasnoyarsk meteorological station.

The correlation coefficients between the wind speeds at point \#5 and the wind speed at the meteorological station are the same as at point \#3 (0.74). But as the downtown wind speed (point \#3) decreases, the wind speed in the industrial region (point \#5) increases. This can be explained by the fact that the downtown building density is twice as high as that in the industrial zone $(20 \%$ and $10 \%$ respectively).

The wind speed at point \#3 decreases on average by $0.9 \mathrm{~m} / \mathrm{s}$, and increases at point \#5 on average by $0.6 \mathrm{~m} / \mathrm{s}$ compared with the speed at the meteorological station. The maximum increase in wind speed at point \#5 is $2.2 \mathrm{~m} / \mathrm{s}$.

On the right bank of Krasnoyarsk, all points (\#7, \#8, \#9 and \#20) are at the same height, about $140 \mathrm{~m}$ above sea level about. The main feature of the wind streams in this part of the city is the dominating southwest and west wind directions for all points.

For example, at point \#7 (Fig. 10) the frequency of winds from the southwest is $23 \%$. However, this point is also characterized by six different wind flow directions. The northeast and southeast wind directions occur often at point \#7 (15\% and 20\% respectively), but they occur infrequently at the meteorological station. 


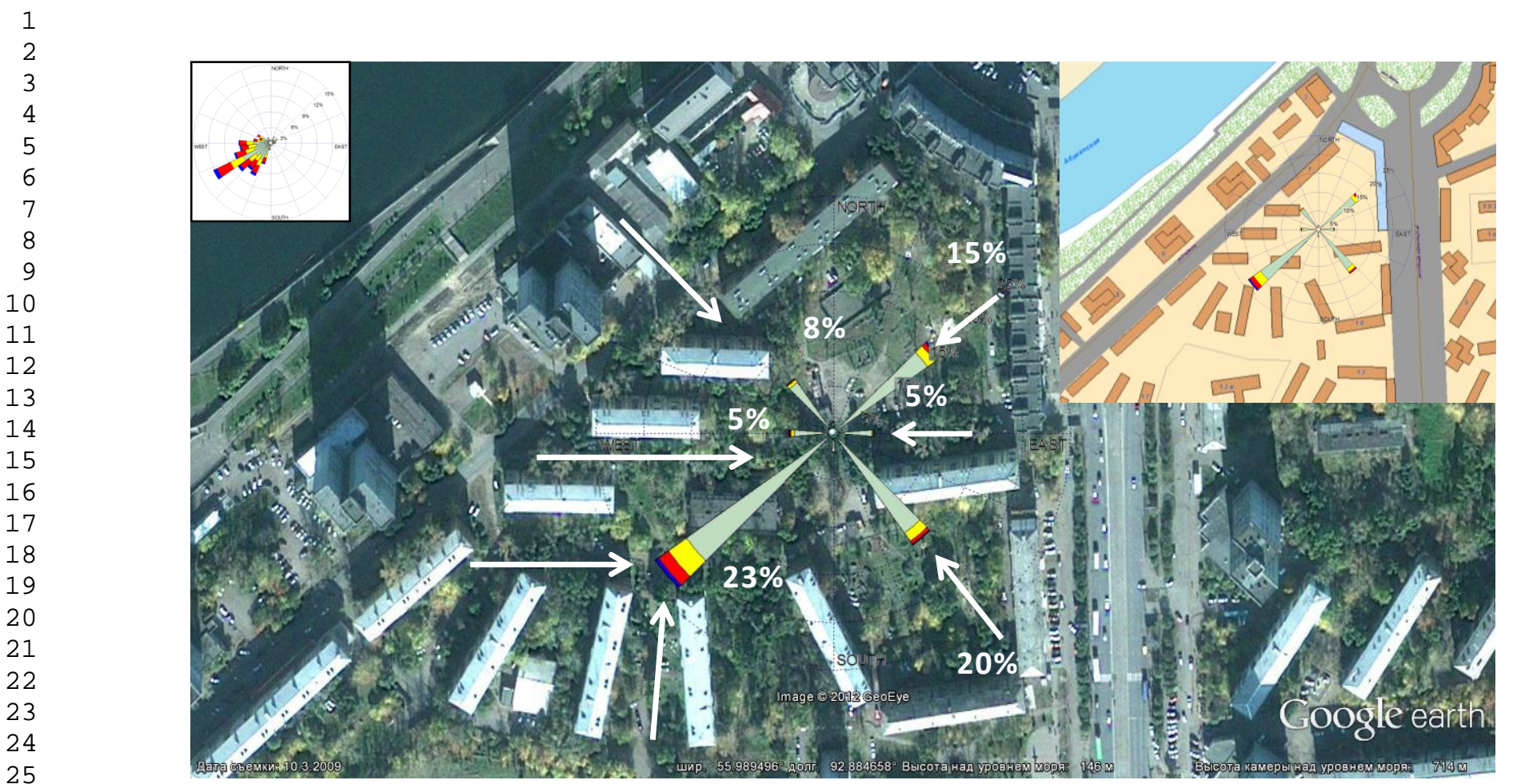

Fig. 10. Wind directions at point \#7 (wind frequencies are shown in percentages). The wind-rose for the meteorological station is in the top left corner. The frequency of calm at point \#7 is about $27 \%$.

Also, as at other points, the building layout around point \#7 contributes to reducing the wind speed, compared to the wind speed at the meteorological station (Fig. 11).

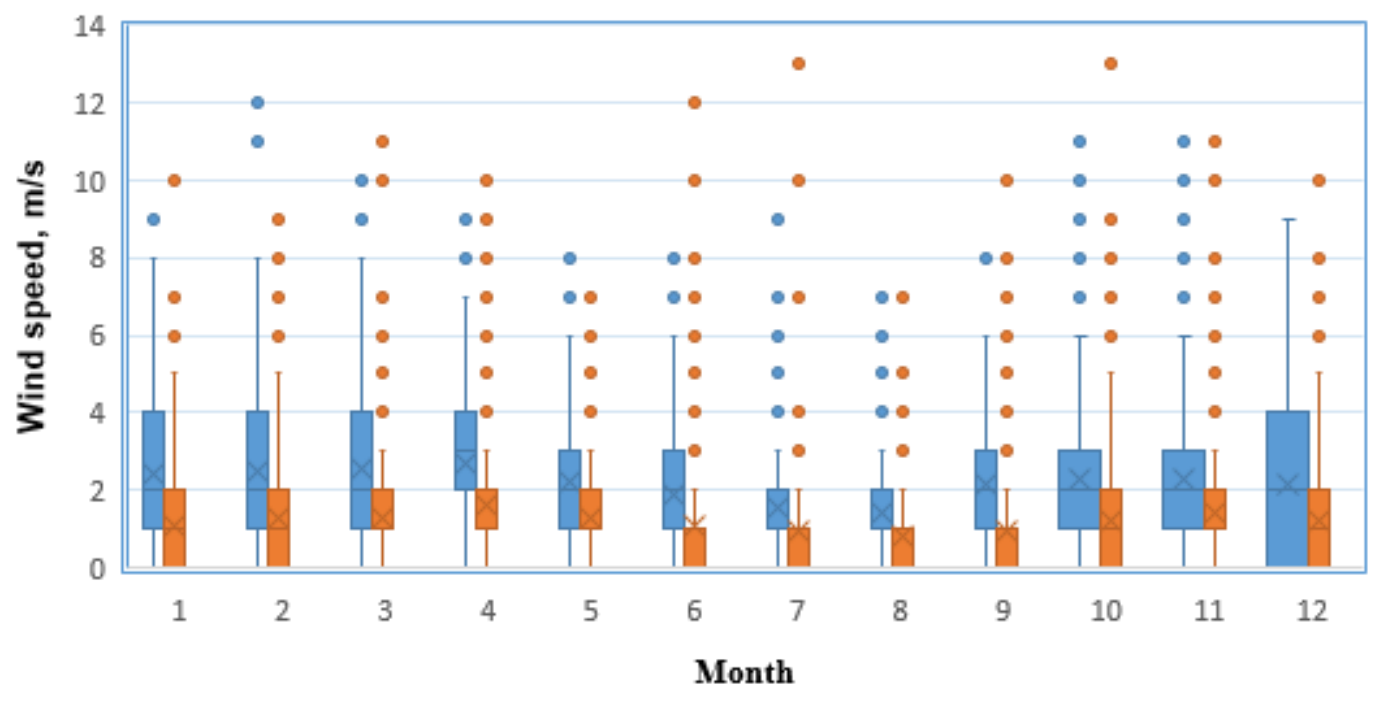

Meteorological station $\square \# 7$

Fig. 11. Yearly average (during 1995-2005) of monthly wind speeds at point \#7 and at the meteorological station.

The correlation coefficient of wind speeds at point \#7 and those at the meteorological station is quite high -0.86 . The wind speed at this point is about $1 \mathrm{~m} / \mathrm{s}$ slower than the speed at the meteorological station. The same reduction of wind speed (approximately $1 \mathrm{~m} / \mathrm{s}$ ) was observed at 
downtown point \#3. This wind speed reduction is probably connected to the shared height above sea level, which is $140 \mathrm{~m}$ for both points and not too tall buildings.

Point \#8, located in the industrial section of Krasnoyarsk's right bank, has only one dominant wind direction, the southwest, with a frequency of $50 \%$ (Fig. 12). The frequency of calm at this point is $30 \%$. The remaining $20 \%$ of wind directions are rare and occur during the calm summer period.

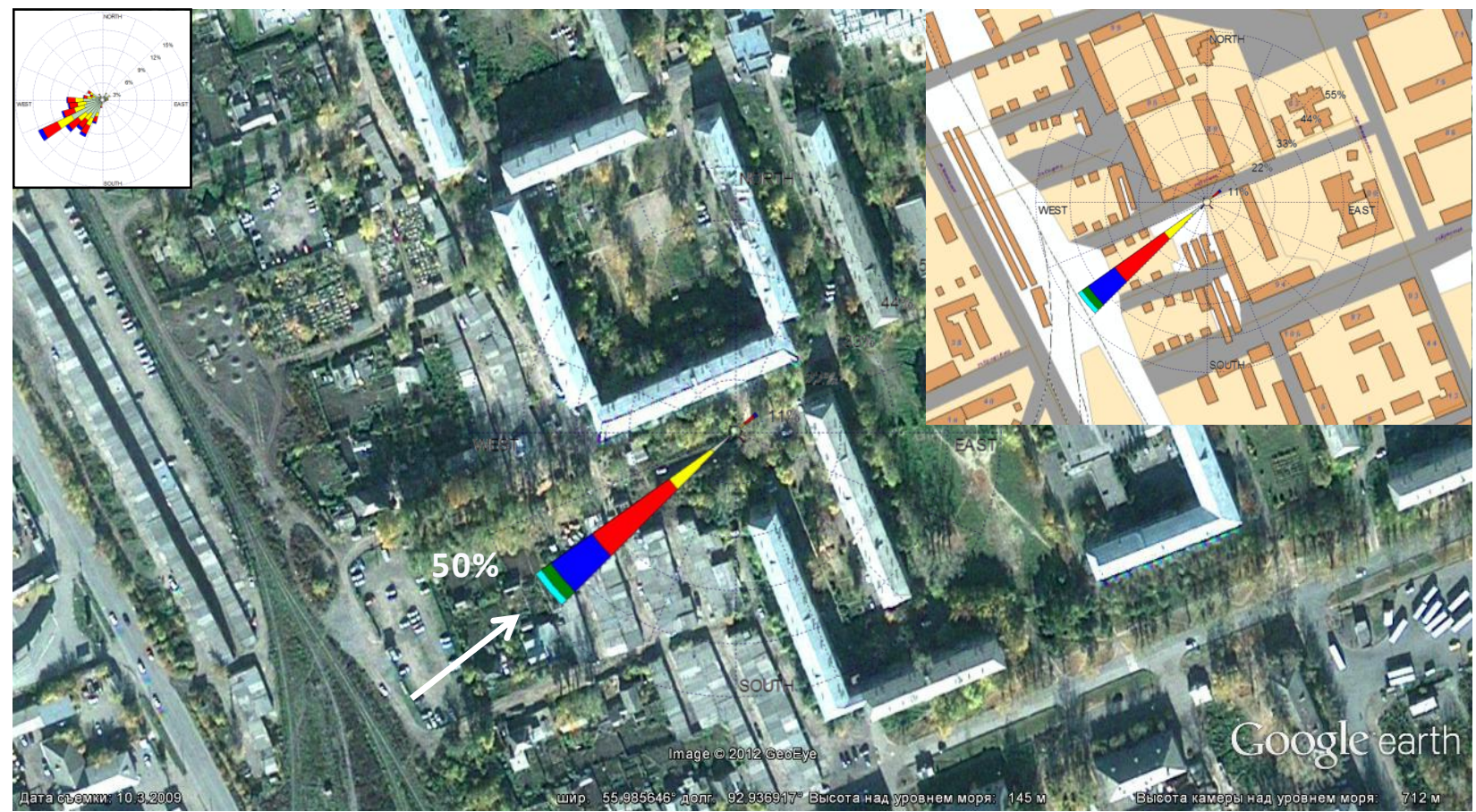

Fig. 12. Wind directions at point \#8 (wind frequencies are shown in percentages). In the top left corner is the wind-rose for the meteorological station. The frequency of calms at point \#8 is about $30 \%$.

The wind speed at point \#8 is higher than the wind speed at the meteorological station by an average of $1 \mathrm{~m} / \mathrm{s}$ (Fig. 13). 


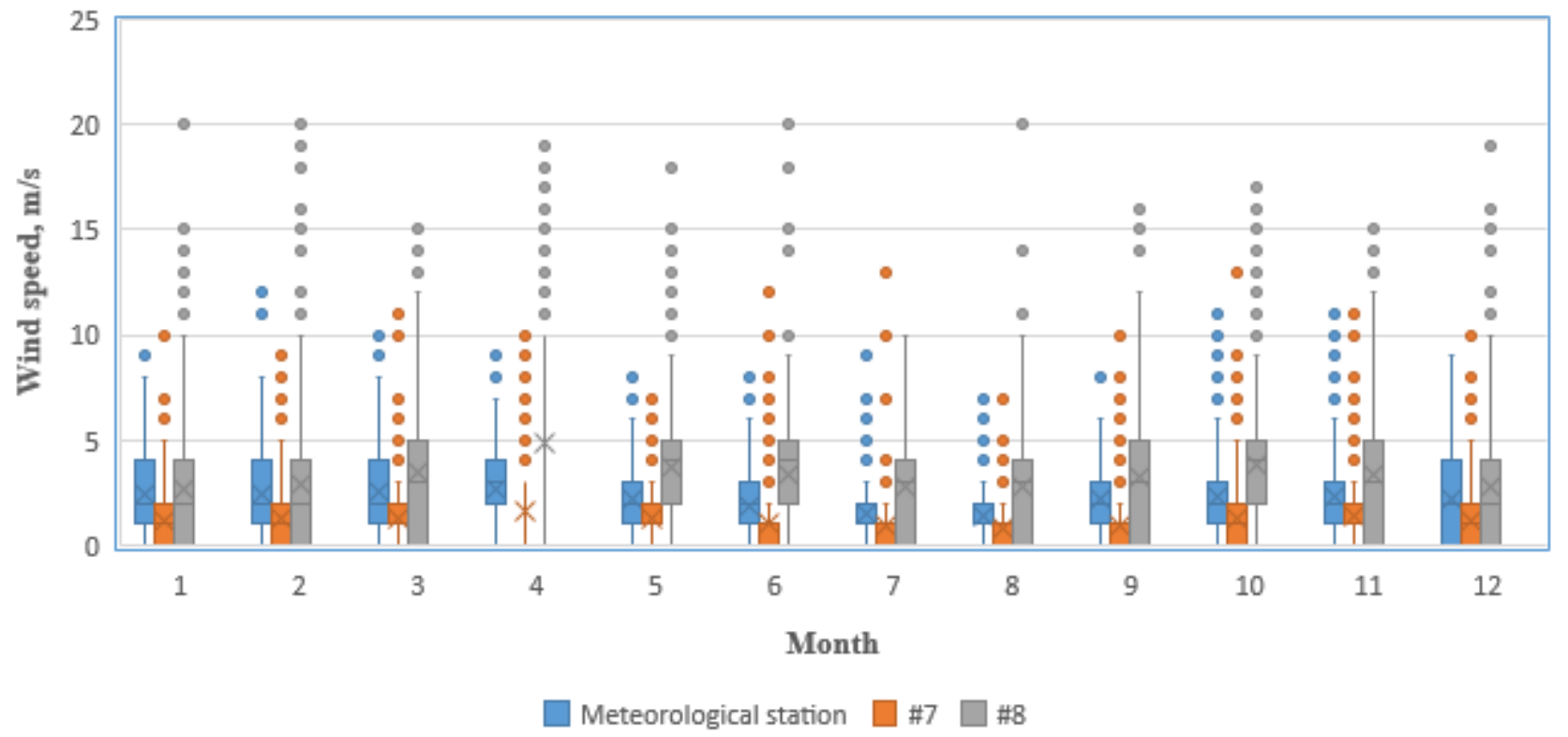

Fig. 13. Yearly average (during 1995-2005) of monthly wind speeds at points \#7 and \#8 and the meteorological station.

Figure 13 shows that the maximum difference in wind speeds between point \#8 and the meteorological station happens in April and is $+2.3 \mathrm{~m} / \mathrm{s}$. The correlation coefficient for wind speeds at point \#8 and the meteorological station is 0.53 .

The distribution of wind directions for point \#9, located in the older part of the city, is shown in Figure 14.

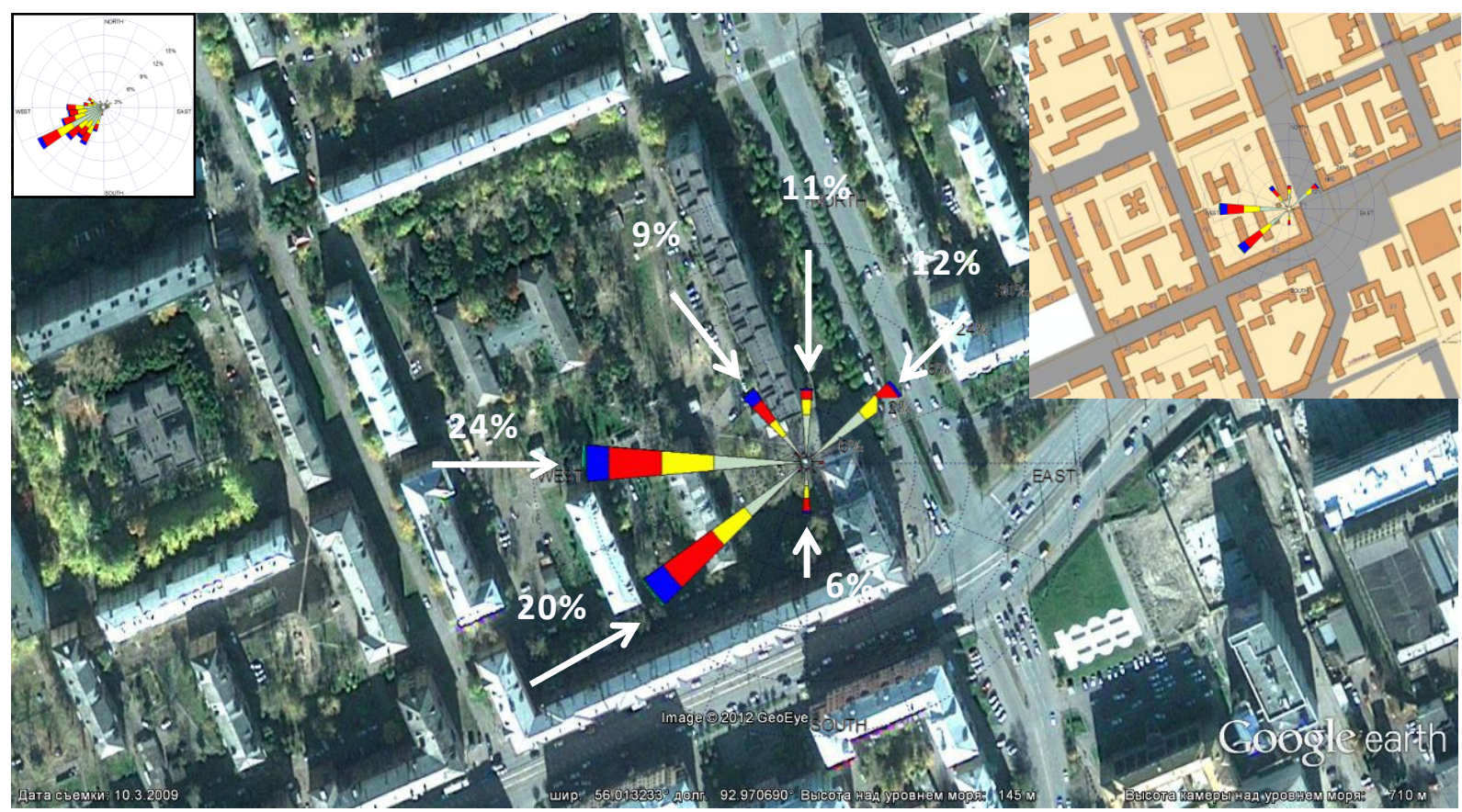

Fig. 14. Wind directions at point \#9 (wind frequencies are shown in percentages). In the top left corner is the wind-rose for the meteorological station. The frequency of calm at point \#9 is about $8 \%$. 
Point \#9 is surrounded by buildings, approximately 30 meters in height, and considerable building density (20\%), and the wind stream is formed by distortions caused by these buildings. At this point, the wind is most likely to be recorded as coming from six directions. The frequency of winds from the southwest is $20 \%$, from the west $-24 \%$, from the northeast $-12 \%$, from the north $11 \%$, from the northwest $-9 \%$ and from the south $-6 \%$.

The frequency of calm at this point is low, about $8 \%$. The wind speed at point \#9 is not significantly faster, but it exceeds the wind speed at the meteorological station by an average of 0.6 m/s (Fig. 15).

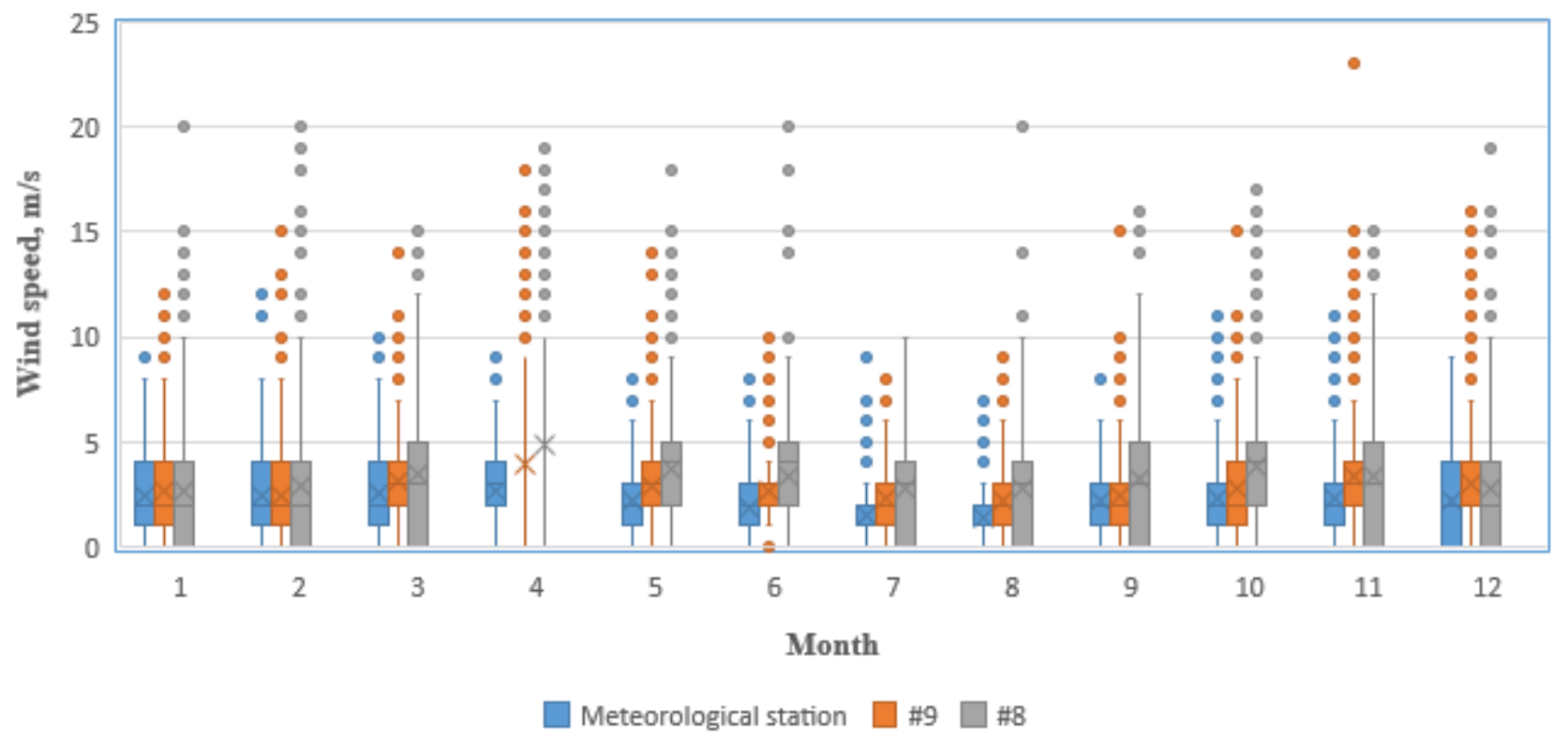

Fig. 15. Yearly average (during 1995-2005) of monthly wind speeds at points \#8 and \#9 and at the meteorological station.

Point \#20 is also in the industrial region of Krasnoyarsk and is surrounded by modern 9story buildings, approximately 30 meters tall, which were built from 1997-2000, with a building density of about 20\%. Until 1997 point \#20 had winds most frequently from the west (65\%) and southwest $(20 \%)$. The frequency of calms was less than $1 \%$. But building construction changed the wind mode around point \#20 (Fig. 16). 


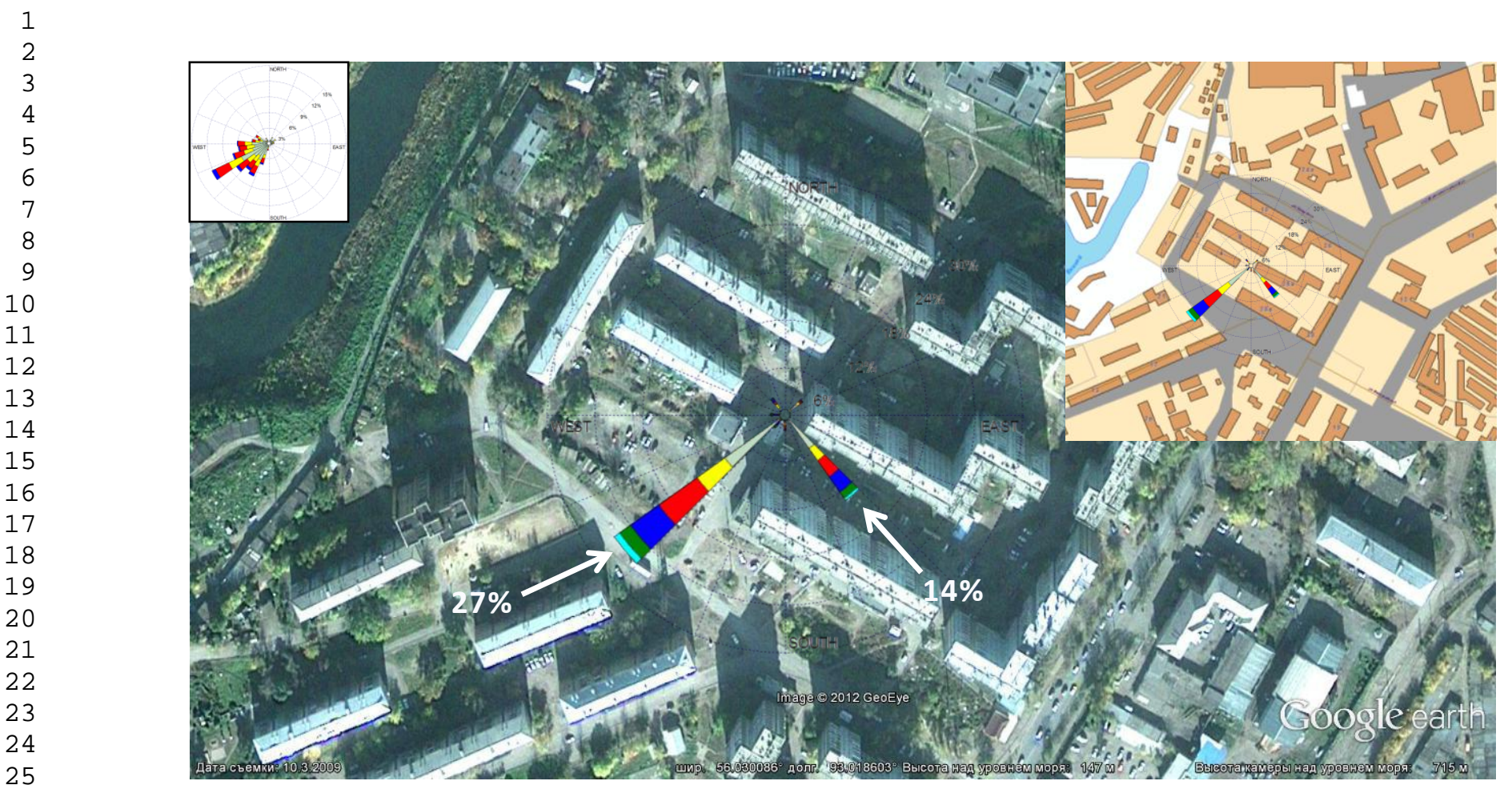

Fig. 16. Wind directions at point \#20 (wind frequencies are shown in percentages). At top left corner is the wind-rose for the meteorological station. The frequency of calms at point $\# 20$ is about $46 \%$.

The dominant winds after 2000 at point \#20 were also from two directions, but the frequency of winds from the southwest sector grew from $20 \%$ to $27 \%$, and the frequency of the western winds decreased from $65 \%$ to $1 \%$, which is uncommon. A new southeastern wind with a frequency of $14 \%$ replaced the vanished western wind. In addition, the construction of very tall buildings led to a sharp increase in the frequency of calms - from $1 \%$ to $46 \%$. The average wind speed at point \#20 decreased from $5 \mathrm{~m} / \mathrm{s}$ (before construction) to $3 \mathrm{~m} / \mathrm{s}$ (after construction) (Fig. 17). 


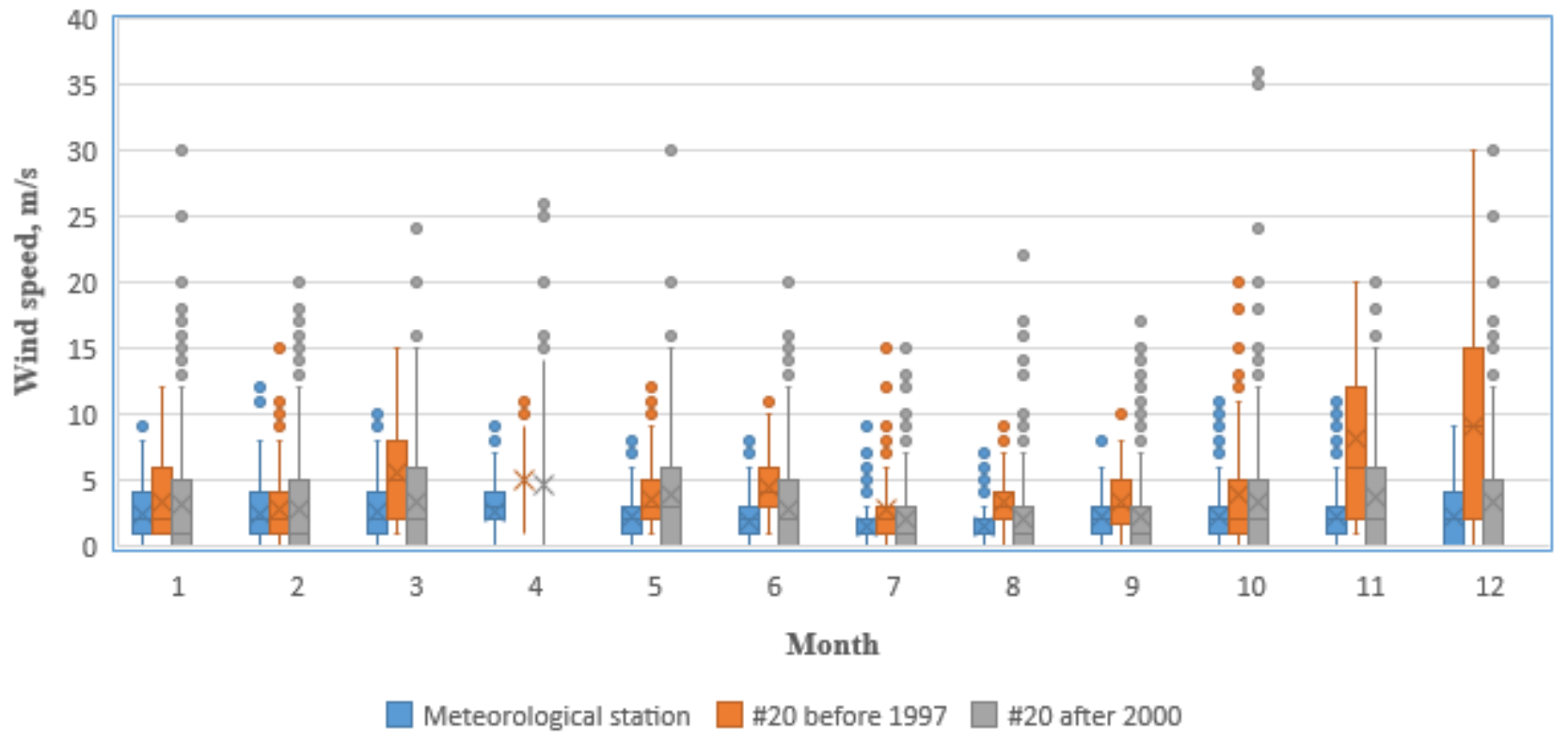

Fig. 17. Annual averages of monthly wind speeds at point \#20 (before 1997 and during 2001-2005) and at the meteorological station (during 1995-2005).

Until 1997, wind speeds with a maximum difference of more than $+5 \mathrm{~m} / \mathrm{s}$ compared to those at the meteorological station were recorded at point \#20. The correlation coefficient between speeds at point \#20 and the meteorological station during this period was 0.48 . After the construction of the buildings around the point was complete, the correlation coefficient increased to 0.85 . The maximum difference between wind speeds at point \#20 and the meteorological station was about +2 $\mathrm{m} / \mathrm{s}$.

The differences in wind speeds at different monitoring stations can be connected to the orientation of elements of urban development (Beller, 2011; Kim, 2014).

\section{Conclusion and discussion}

This research on how Krasnoyarsk urban buildings transform wind streams showed that wind streams passing through the city undergo significant changes in wind directions and speeds. The number of possible wind directions at a concrete point is determined by the building configuration. Urban wind speeds can increase or decrease in relation to the "free" wind speed at the meteorological station (Tab. 1). 
Table 1

Features of transformation of wind streams in city.

The distinctive feature of wind streams in the built-up areas of Krasnoyarsk is that they correlate to various extents with the wind speed at the meteorological station. However, point \#21 differs from the others, in that no correlation has been found for it, which is perhaps due to the tallest single building (height about $30 \mathrm{~m}$ ) in the southwest sector being located within 20 meters of that point.

Four of the seven points (\#5, \#8, \#9 and \#20) show an increased wind speed of approximately $1 \mathrm{~m} / \mathrm{s}$ compared to the wind speed at the meteorological station. At points \#21, \#3 and \#7 the wind speed decreases. The greatest reduction of wind speed is observed at point \#21 as well as the greatest frequency of calms (60\%), which is four times greater than at the meteorological station.

Studying the wind directions and speeds and the morphological features of the built-up areas allows us to explicitly determine the effects of splitting wind flows at specific buildings (points \#3 and \#9) and their distortions on the edges of buildings, and to estimate the impact of permeability in built-up areas (Taseiko et al., 2009).

In general, the winds in the built-up area are characterized by steady directional flows that are not representative of the patterns recorded at the meteorological station and also by an increased frequency of calms (in all points except point \#9). The frequency of calms at point \#9 is almost twice that of the meteorological station.

A detailed examination of how natural wind streams are transformed by the influence of local morphological features of urban buildings allows us to better understand the problems of describing the processes of urban winds' transformation. This paper has shown the full presentation of transformation of the undisturbed wind flow caused by non-uniform relief and building arrangements. This result can be used to verify of numerical simulation models for air pollution 
dispersion and to further use this information to better parametrize a wide range of problems of wind flows in urban areas.

\section{Acknowledgement}

Work is supported by the Russian Foundation for Basic Research and by the Krasnoyarsk Regional scientific fund No. 15-45-04034 r_sibir_a.

\section{References}

Bady, M., Kato, S., Takahashi, T., Huang, H., 2011. An experimental investigation of the wind environment and air quality within a densely populated urban street canyon. J. Wind Eng. Ind. Aerodyn. 99, 857-867.

Beller, C. (2011). Urban Wind Energy. Danmarks Tekniske Universitet, Ris $\varnothing$ Nationallaboratoriet for Bæredygtig Energi. (Ris $\varnothing-\mathrm{PhD}$; No. 89(EN)).

Branis, M., Rezacova, P., Lazaridis, M., 2014. The effect of source type and source strength on inhaled mass of particulate matter during episodic indoor activities. Indoor Built Environ. 23, 1106-1116.

Claus, J., Coceal, O., Thomas, T.G., Branford, S., Belcher, S.E., Castro, I.P., 2012. Wind-Direction Effects on Urban-Type Flows. Boundary-Layer Meteorol. 142, 265-287.

Simiu, Emil. Robert H. Scanlan. 1996. Winds Effects on Structures: Fundamentals and Applications to Design. Wiley

Fung, W., Lam, K., Hung, W., Pang, S., Lee, Y., 2006. Impact of urban temperature on energy consumption of Hong Kong. Energy 31, 2623-2637. doi:10.1016/j.energy.2005.12.009

Gadian, A., Dewsbury, J., Featherstone, F., Levermore, J., Morris, K., Sanders, C., 2004. Directional persistence of low wind speed observations. J. Wind Eng. Ind. Aerodyn. 92, 1061-1074.

Gao, Y., Yao, R., Li, B., Turkbeyler, E., Luo, Q., Short, A., 2012. Field studies on the effect of built forms on urban wind environments. Renew. Energy 46, 148-154.

Kato, S., Huang, H., 2009. Ventilation efficiency of void space surrounded by buildings with wind blowing over built-up urban area. J. Wind Eng. Ind. Aerodyn. 97, 358-367.

Kim, H. 2014. Urban form, wind, comfort, and sustainability: the San Francisco experience. Doctor of Philosophy Dissertation. Dept. of City and Regional Planning, University of California, Berkeley. www.escholarship.org/uc/item/0h50x0h8.

Klimat Krasnoyarska. Leningrad. Gidrometeoizdat, 1982 - 232 s.

Kolokotroni, M., Giannitsaris, I., Watkins, R., 2006. The effect of the London urban heat island on building summer cooling demand and night ventilation strategies. Sol. Energy 80, 383-392.

Jacobson, Mark Z. 2005. Fundamentals of Atmospheric Modeling. Journal of Atmospheric and Solar-Terrestrial Physics. Cambridge University Press.

Lo Brano, V., Orioli, A., Ciulla, G., Culotta, S., 2011. Quality of wind speed fitting distributions for the urban area of Palermo, Italy. Renew. Energy 36, 1026-1039.

Memon, R.A., Leung, D.Y.C., 2010. Impacts of environmental factors on urban heating. J. Environ. Sci. 22, 1903-1909. doi:10.1016/S1001-0742(09)60337-5

Nowak, D.J., Crane, D.E., Stevens, J.C., 2006. Air pollution removal by urban trees and shrubs in the United States. Urban For. Urban Green. 4, 115-123. doi:10.1016/j.ufug.2006.01.007 
OND-86. Metodika rascheta koncentracij $\mathrm{v}$ aimosfernom vozduhe vrednyh veshchestv Soderzhashchihsya v vybrosah predpriyatij OND - 86 - Leningrad Goskomgtdromet 1987 $17 \mathrm{~s}$.

Plate, E.J., 1999. Methods of investigating urban wind fields-physical models, в: Atmospheric Environment. Elsevier Science Ltd, pp 3981-3989.

Priyadarsini, R., Hien, W.N., Wai David, C.K., 2008. Microclimatic modeling of the urban thermal environment of Singapore to mitigate urban heat island. Sol. Energy 82, 727-745.

Raputa, V.F., Talovskaya, A. V, Kokovkin, V. V, Yazikov, E.G., 2011. Analysis of observations of the snow cover pollution by aerosol particles at the territory of Tomsk-city and Seversk-city environments. Opt. Atmos. i Okeana 24, 74-78.

Shahrestani, M., Yao, R., Luo, Z., Turkbeyler, E., Davies, H., 2015. A field study of urban microclimates in London. Renew. Energy 73, 3-9.

Shilton, V., Giess, P., Mitchell, D., Williams, C., 2002. The relationships between indoor and outdoor respirable particulate matter: Meteorology, chemistry and personal exposure. Indoor Built Environ. 11, 266-274.

Taseiko, O. V, Mikhailuta, S. V, Pitt, A., Lezhenin, A.A., Zakharov, Y. V, 2009. Air pollution dispersion within urban street canyons. Atmos. Environ. 43, 245-252. doi:10.1016/j.atmosenv.2008.09.076

Yang, L., Li, Y., 2011. Thermal conditions and ventilation in an ideal city model of Hong Kong, в: Energy and Buildings. pp 1139-1148.

Weather archive. http://meteo.infospace.ru

WRPLOT View, Version 7.0.0. https://www.weblakes.com/products/wrplot/index.html 


\section{Figure}

Click here to download Figure: Figure 1.docx

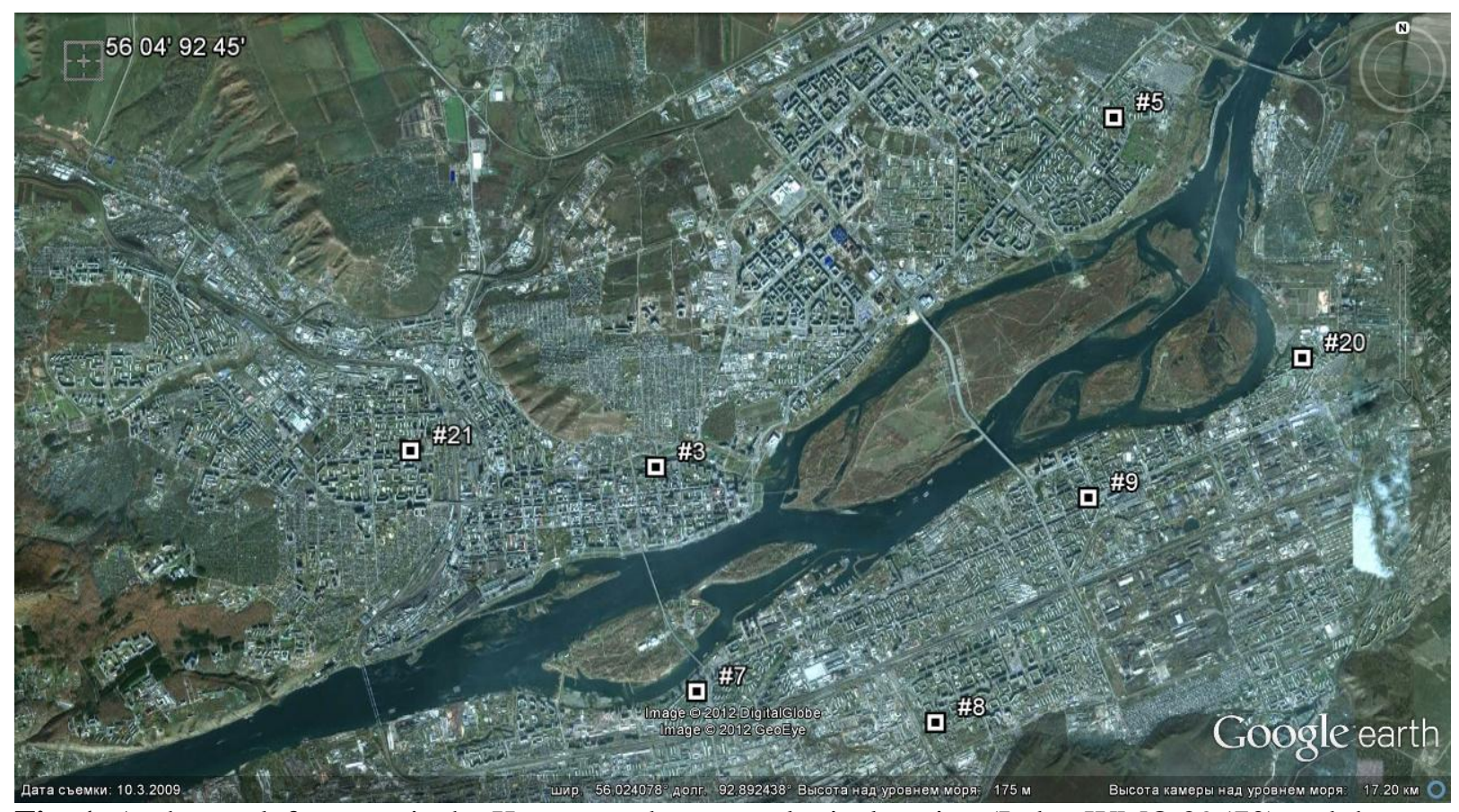

Fig. 1. At the top left corner is the Krasnoyarsk meteorological station (Index WMO 29570) and the numbered points are the city weather and air pollution monitoring stations in Krasnoyarsk City. 
Figure
Click here to download Figure: Figure 2.docx

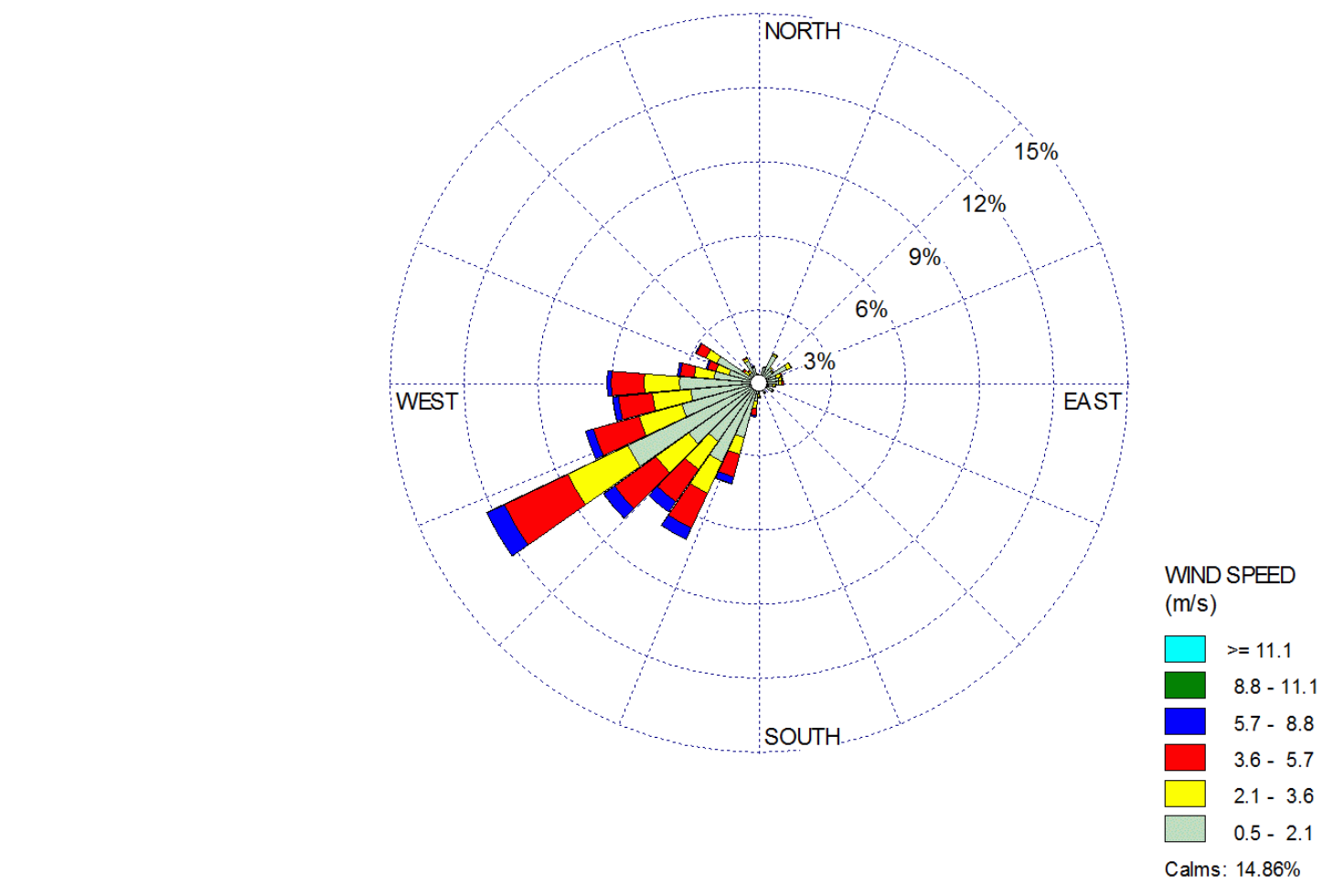

Fig. 2. Frequency of wind directions at the Krasnoyarsk meteorological station (from 1995 to 2010)

Fig. 2. Frequency of wind directions at the Krasnoyarsk meteorological station (from 1995 to 2010)

WIND SPEE

Calms: $14.86 \%$

(

$8-11.1$

$6-5.7$

$1-3.6$

$-5.1$

(1)

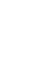

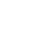


NORTH

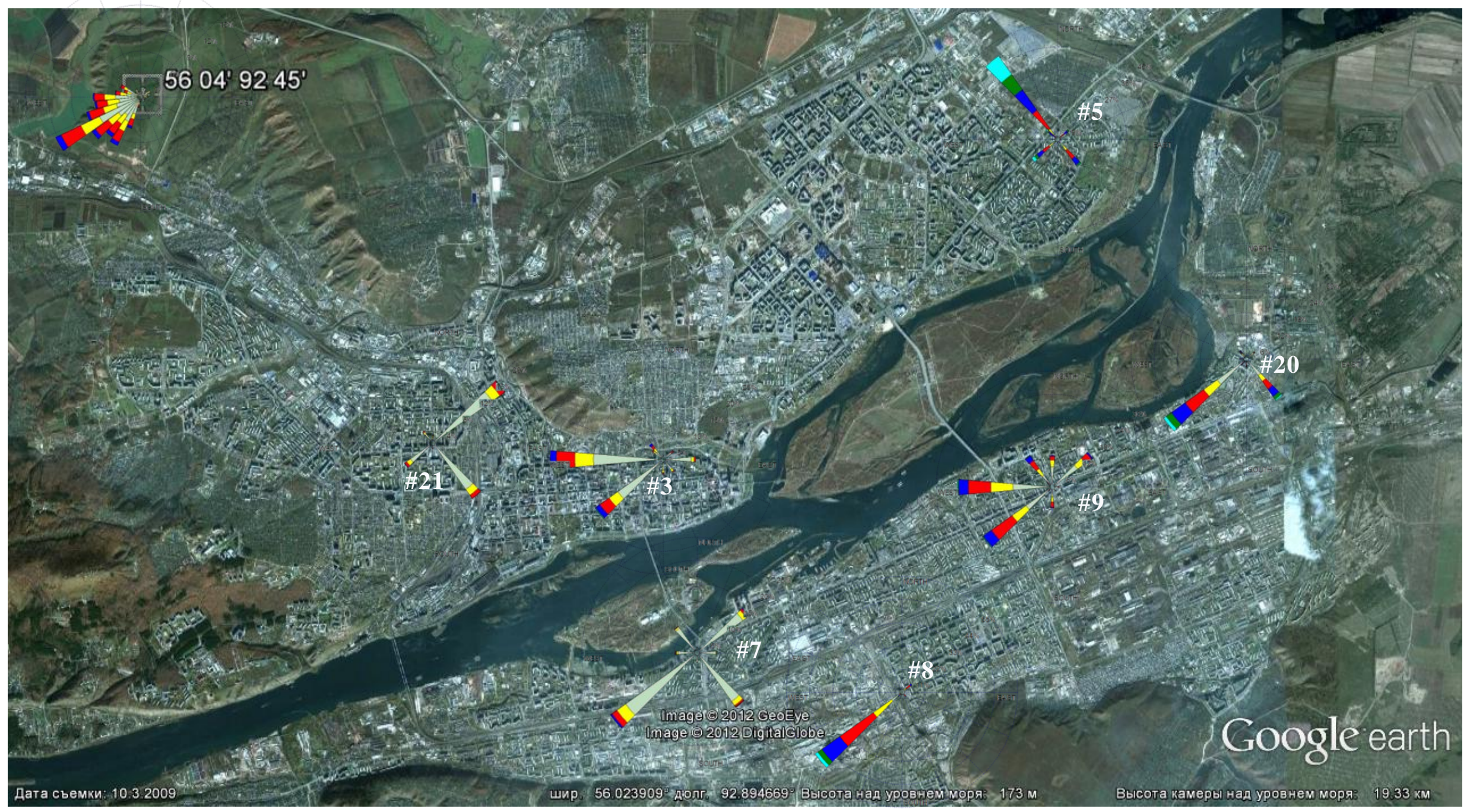

Fig. 3. The directions of winds at the meteorological station and in urban areas of Krasnoyarsk (data from 1995-2010 are averaged) 


\section{Figure}

Click here to download Figure: Figure 4.docx

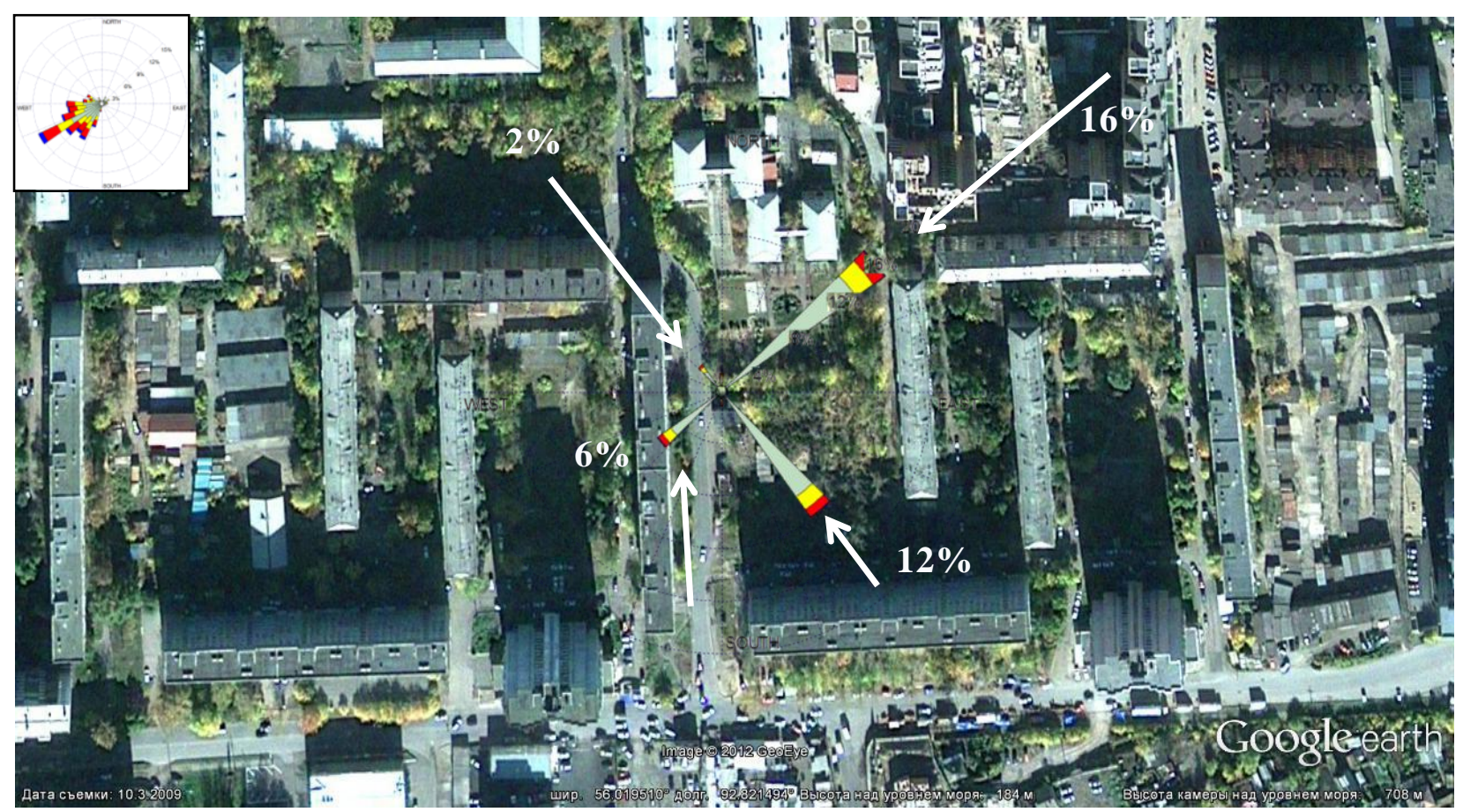

Fig. 4. Wind directions at point \#21 (frequencies are shown in percentages). In the top left corner is the wind-rose for the meteorological station. The percentage of calm at point \#21 is greater than $60 \%$. 
Figure
Click here to download Figure: Figure 5.docx

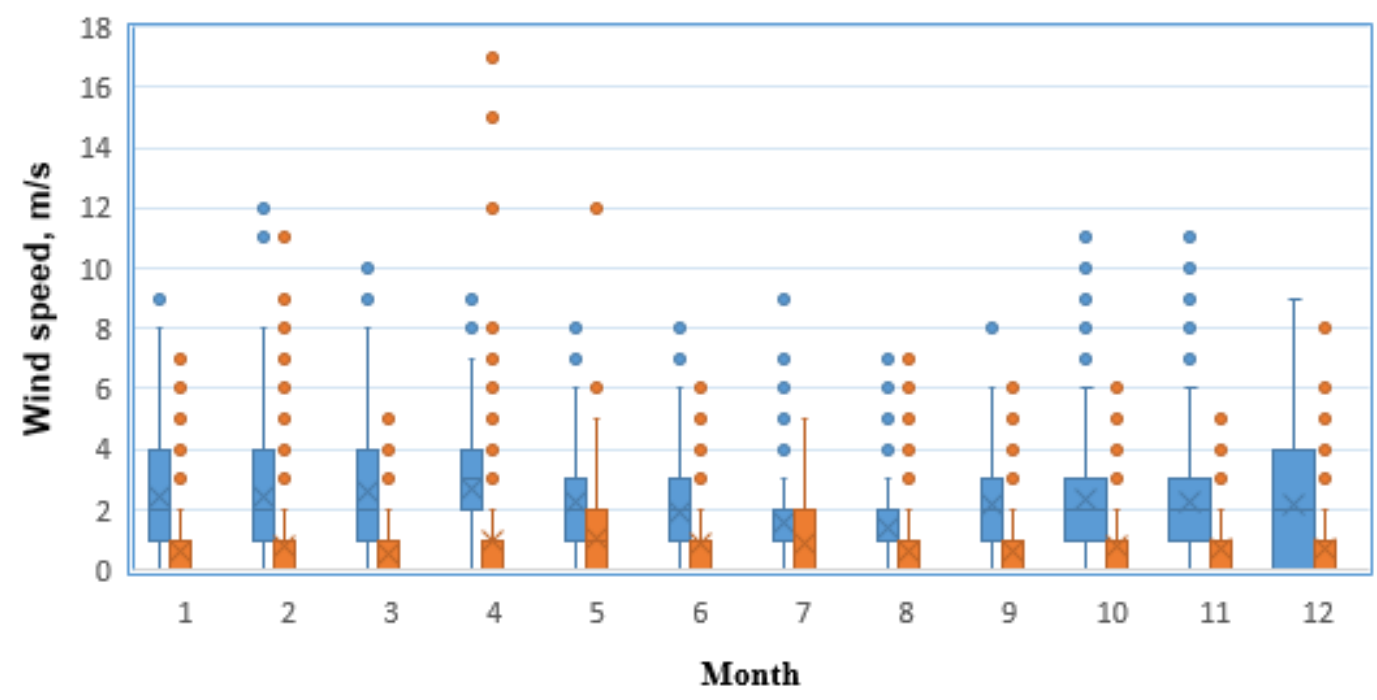

Meteorological station $\square \# 21$

Fig. 5. Average (during 1995-2010) of monthly wind speeds at point $\# 21$ and at the Krasnoyarsk meteorological station. 


\section{Figure}

Click here to download Figure: Figure 6.docx

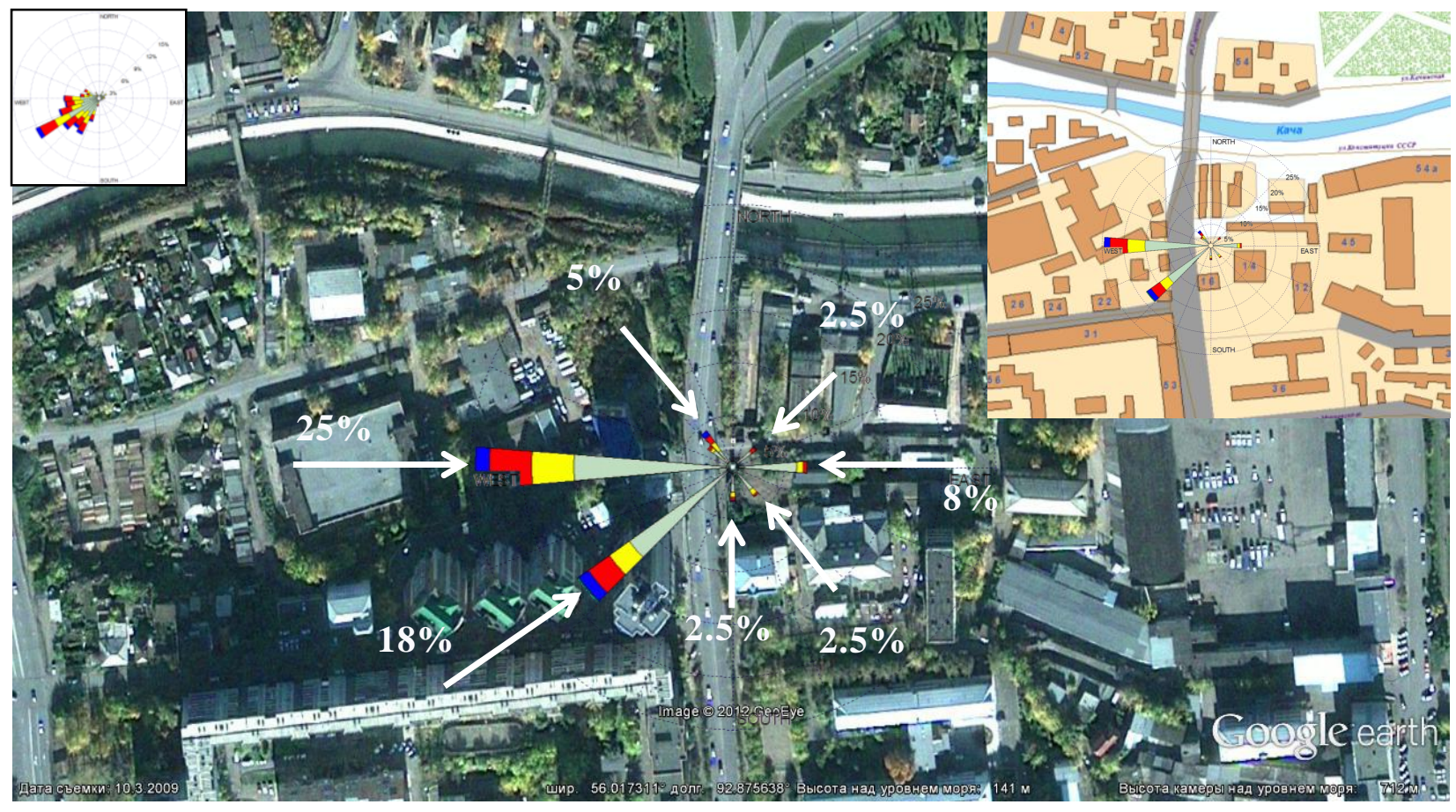

Fig. 6. Wind directions at point \#3 (wind frequencies are shown in percentage). At the top left corner is the wind rose for the Krasnoyarsk meteorological station. The frequency of calm at point \#3 is about $30 \%$. 
Figure
Click here to download Figure: Figure 7.docx

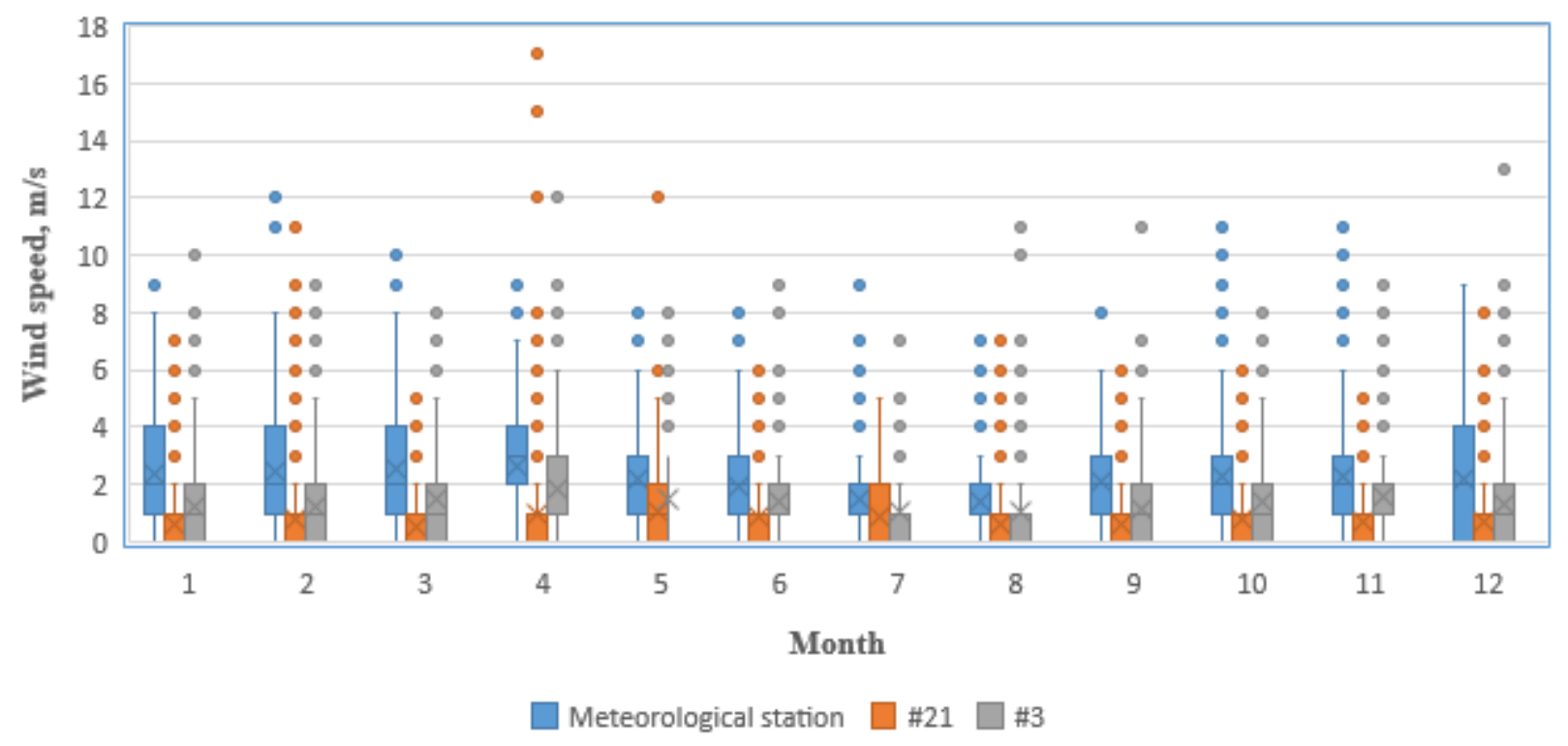

Fig. 7. Monthly averages (during 1995-2010) of yearly wind speeds at points \#3, \#21 and the meteorological station. 


\section{Figure}

Click here to download Figure: Figure 8.docx

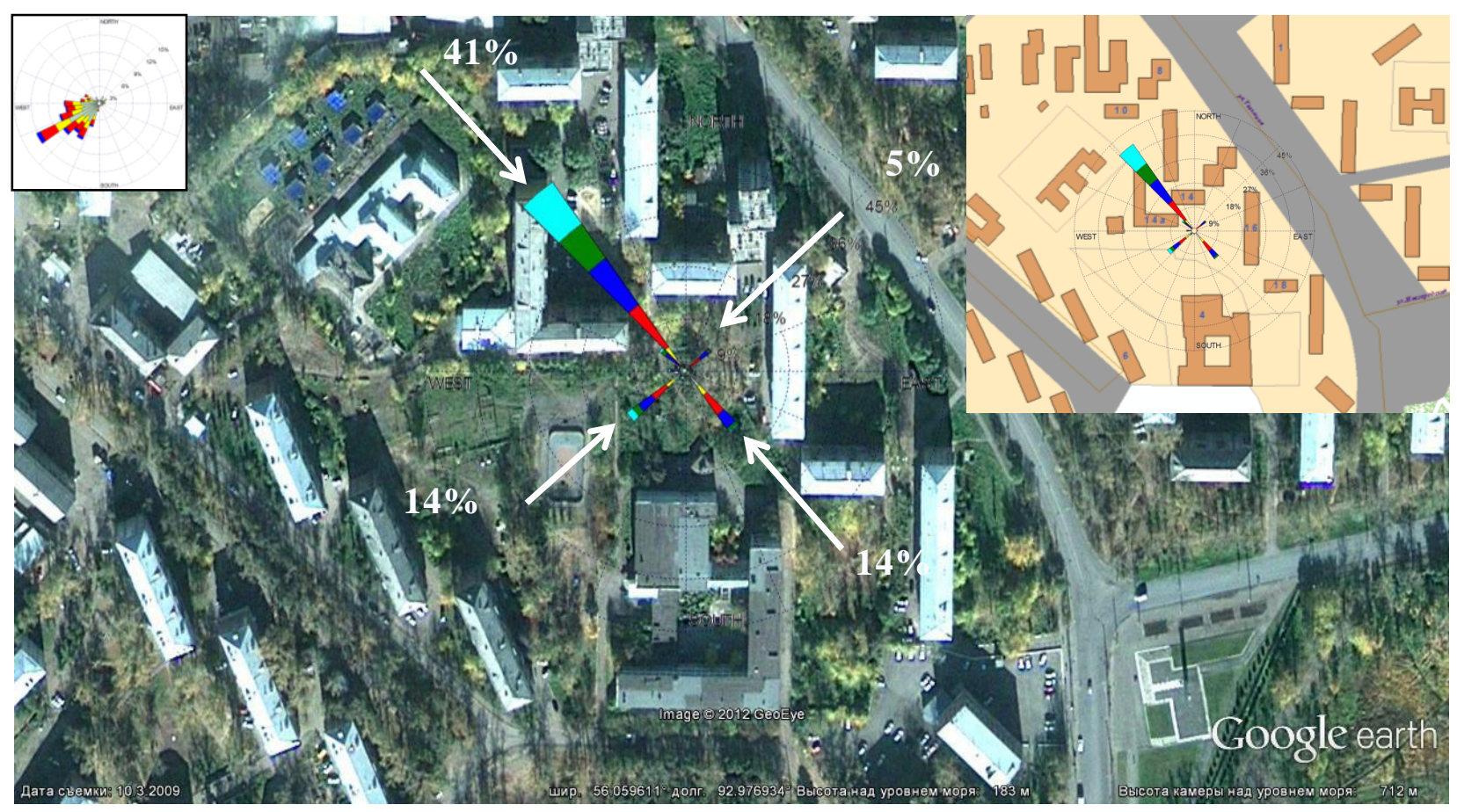

Fig. 8. Wind directions at point \#5 (wind frequencies are shown in percentages). The wind- rose for the meteorological station is shown in the top left corner. The frequency of calm at point \#5 is about $18 \%$. 
Figure
Click here to download Figure: Figure 9.docx

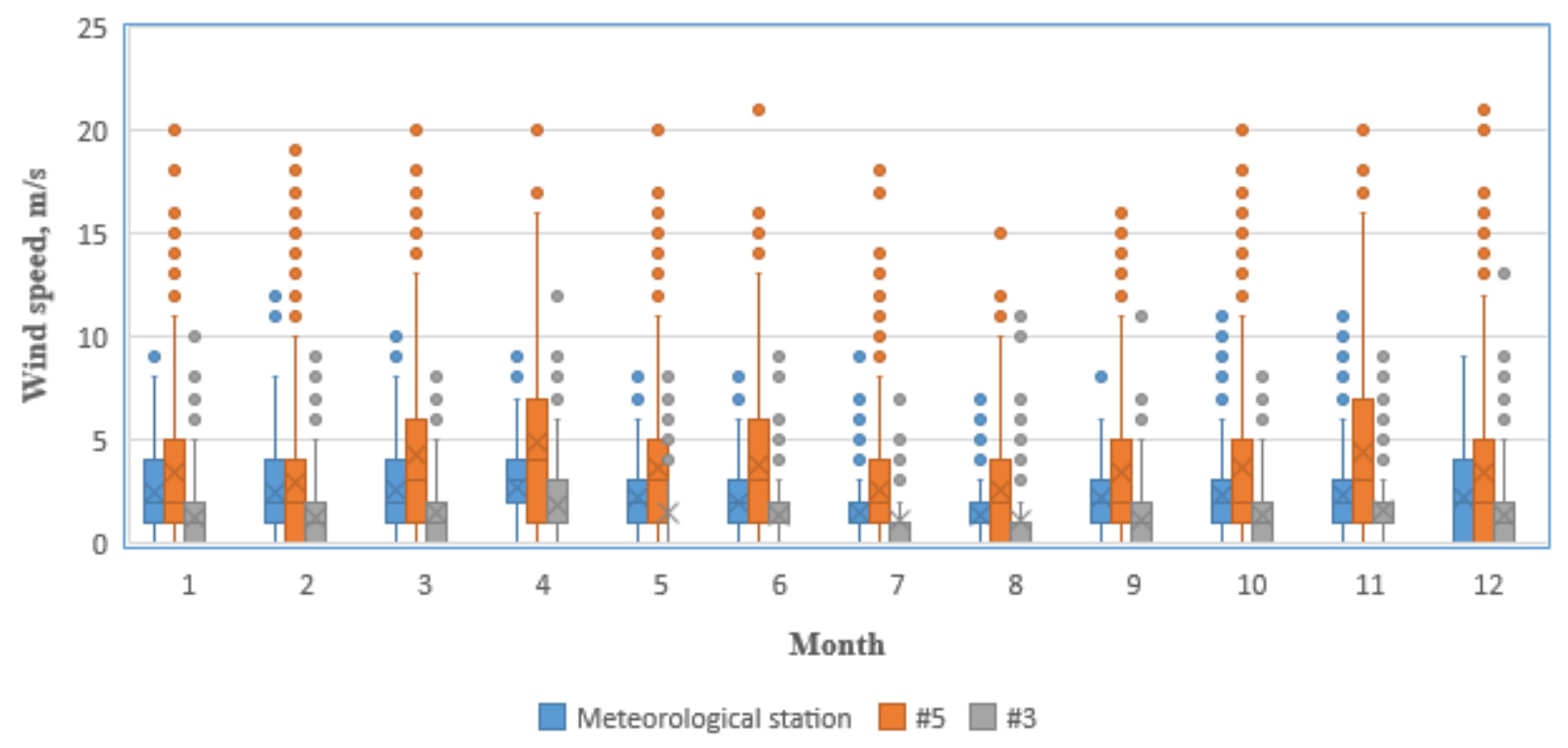

Fig. 9. Yearly averages (during 1995-2010) of monthly wind speeds at points \#3, \#5 and the Krasnoyarsk meteorological station. 


\section{Figure}

Click here to download Figure: Figure 10.docx

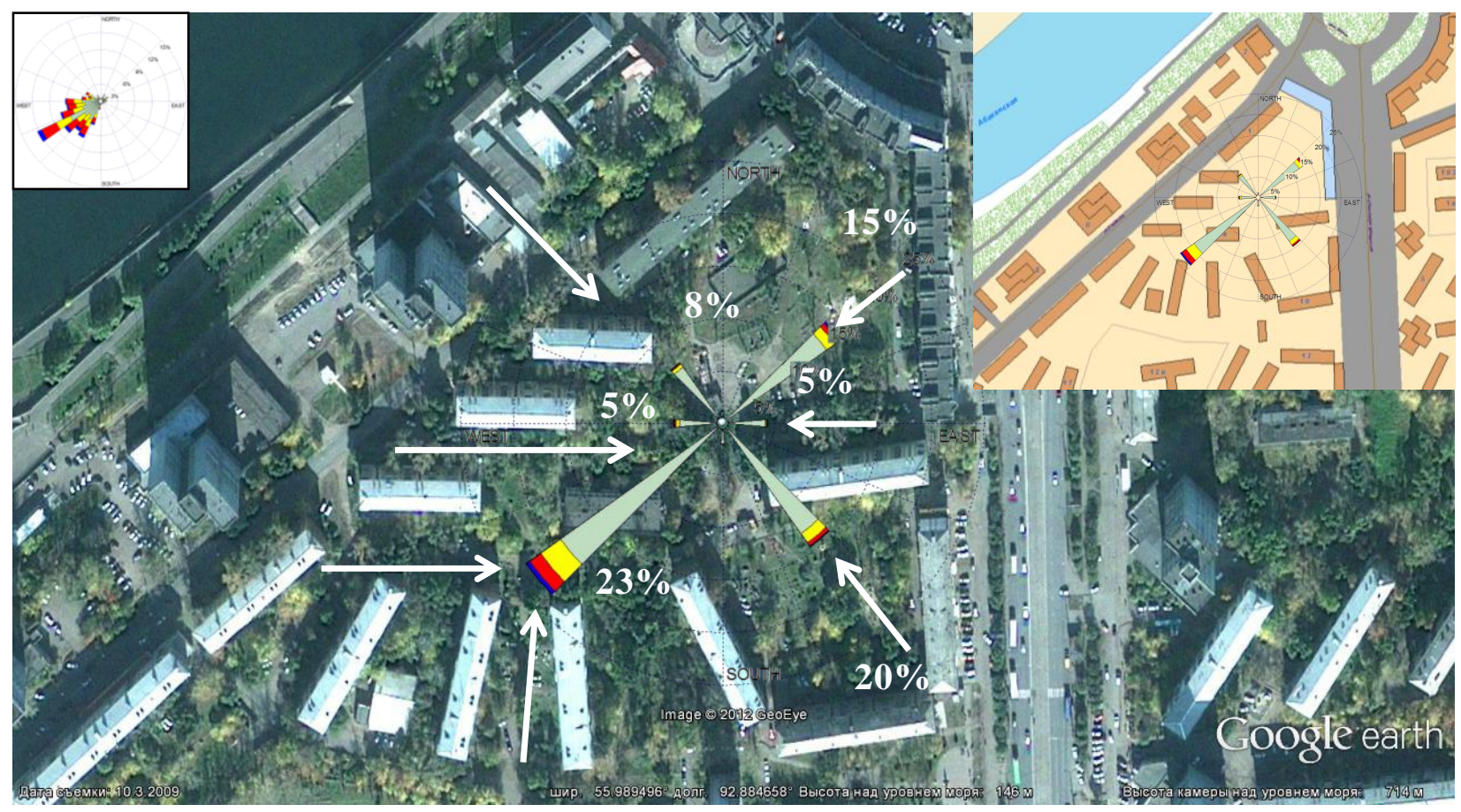

Fig. 10. Wind directions at point \#7 (wind frequencies are shown in percentages). The wind-rose for the meteorological station is in the top left corner. The frequency of calm at point \#7 is about $27 \%$. 


\section{Figure}

Click here to download Figure: Figure 11.docx

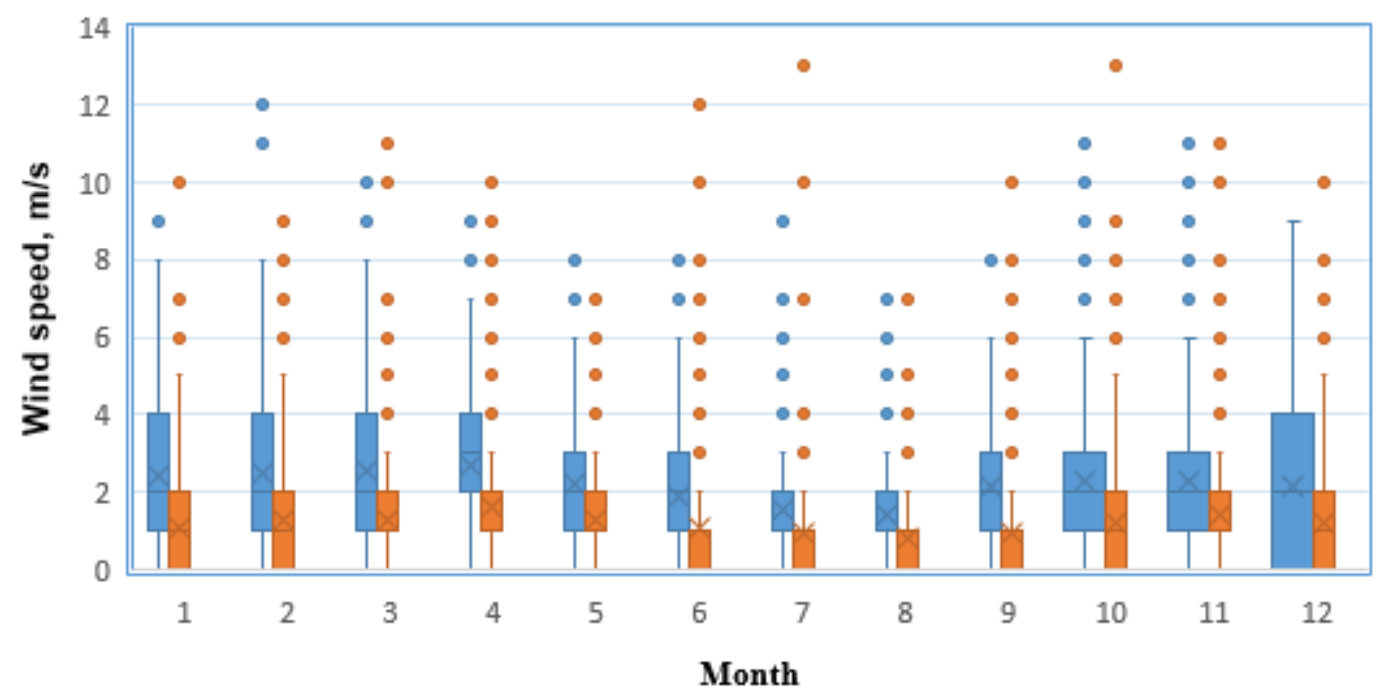

Meteorological station $\square \# 7$

Fig. 11. Yearly average (during 1995-2005) of monthly wind speeds at point \#7 and at the meteorological station. 


\section{Figure}

Click here to download Figure: Figure 12.docx

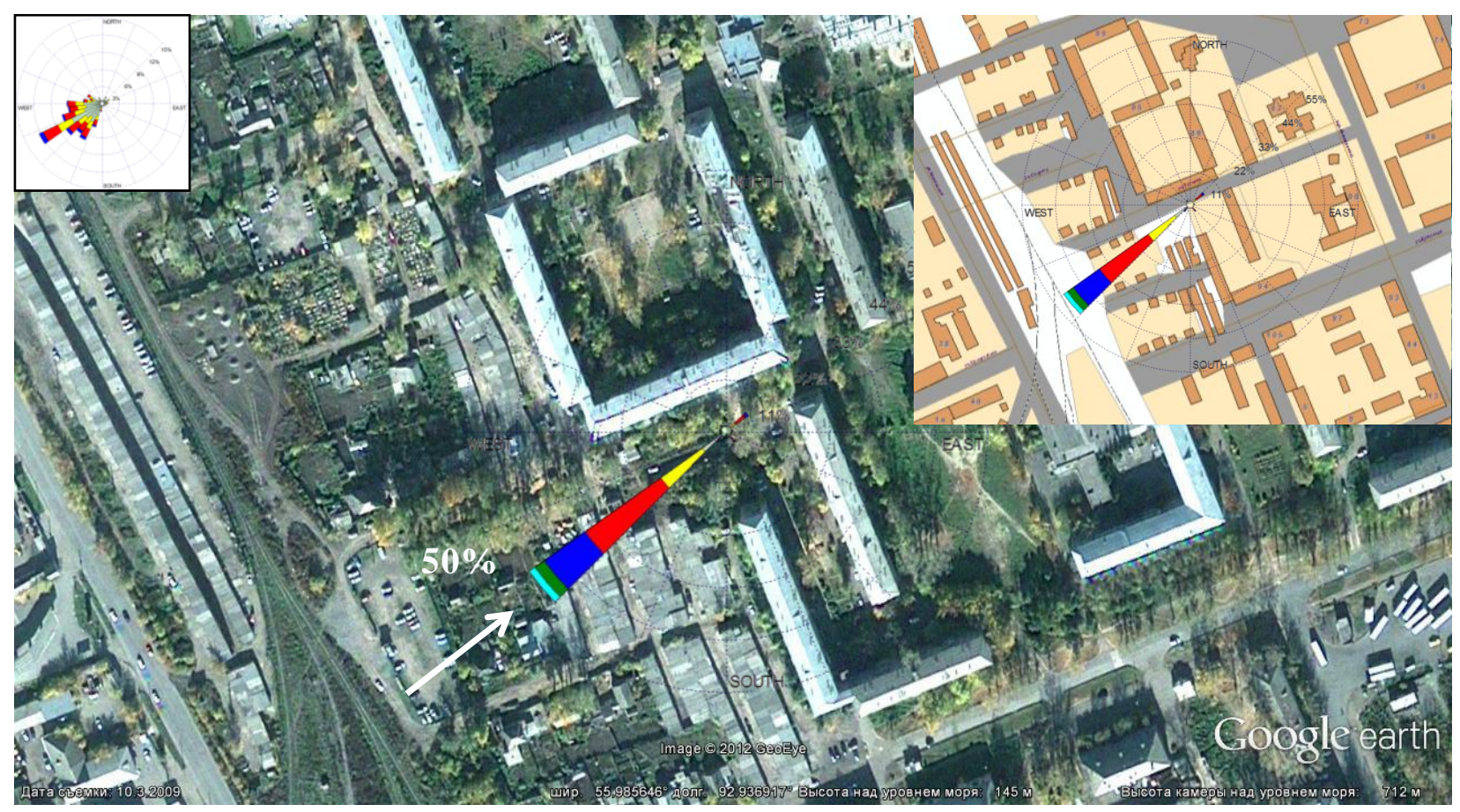

Fig. 12. Wind directions at point \#8 (wind frequencies are shown in percentages). In the top left corner is the wind-rose for the meteorological station. The frequency of calms at point \#8 is about $30 \%$. 
Figure
Click here to download Figure: Figure 13.docx

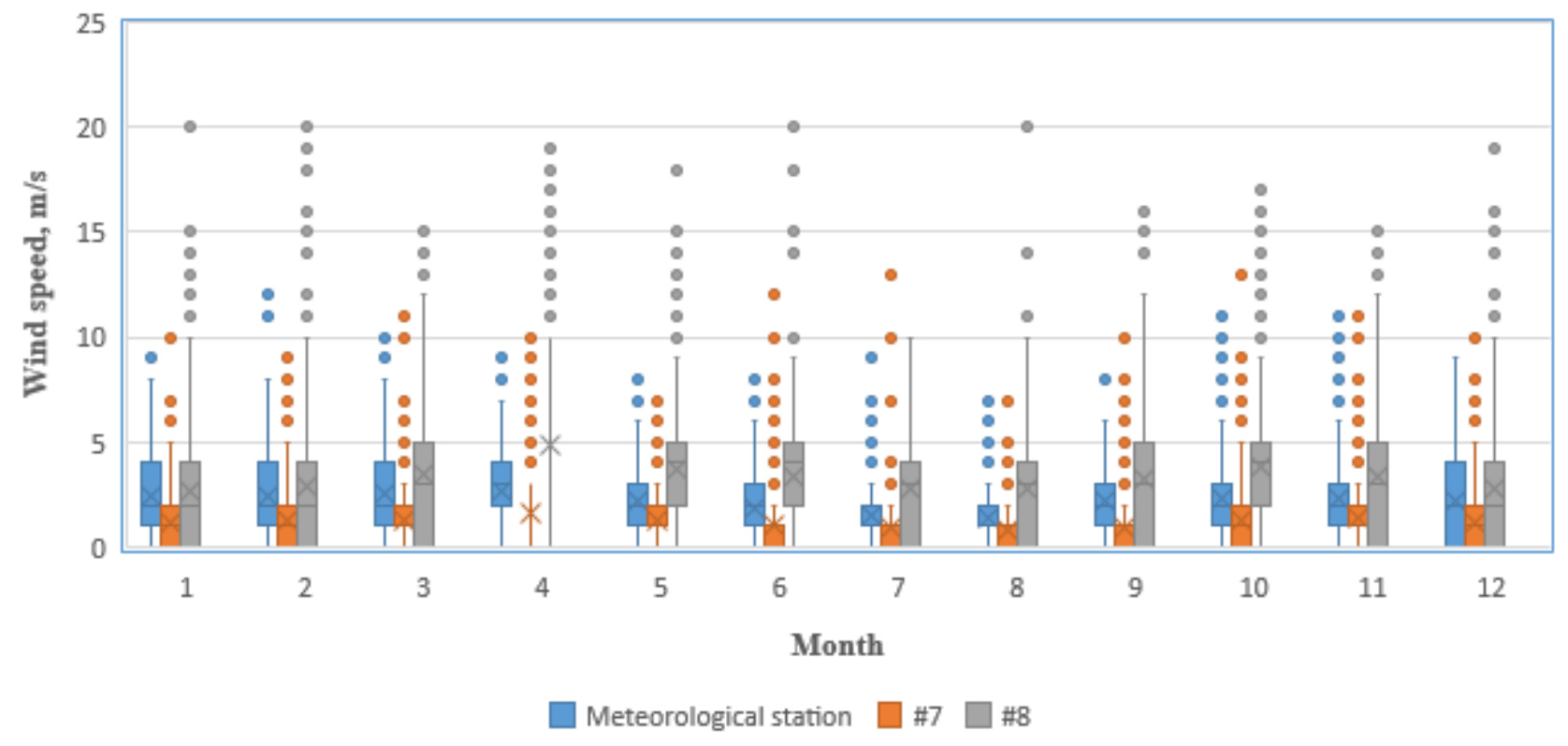

Fig. 13. Yearly average (during 1995-2005) of monthly wind speeds at points \#7 and \#8 and the meteorological station. 


\section{Figure}

Click here to download Figure: Figure 14.docx

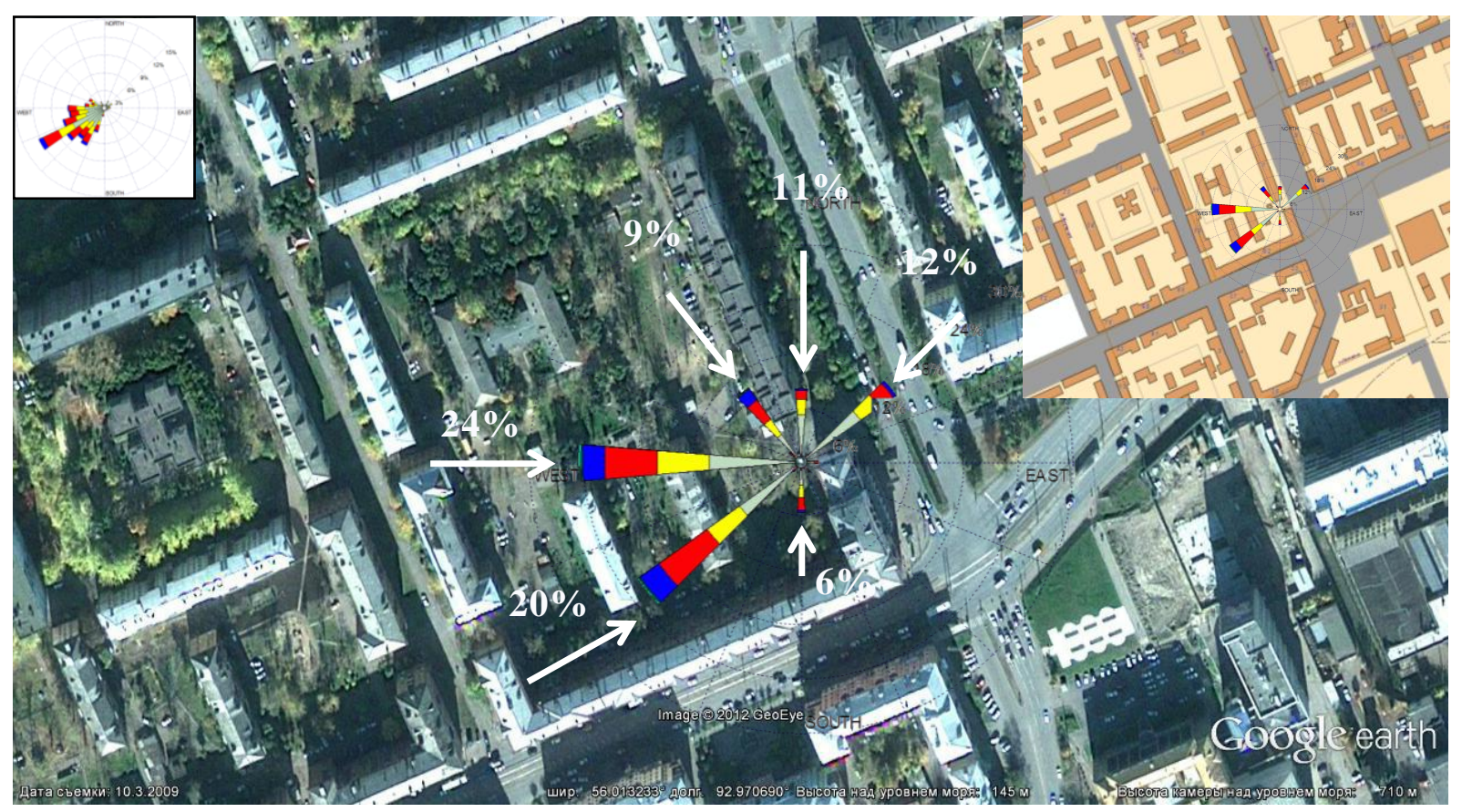

Fig. 14. Wind directions at point \#9 (wind frequencies are shown in percentages). In the top left corner is the wind-rose for the meteorological station. The frequency of calm at point \#9 is about $8 \%$. 
Figure
Click here to download Figure: Figure 15.docx

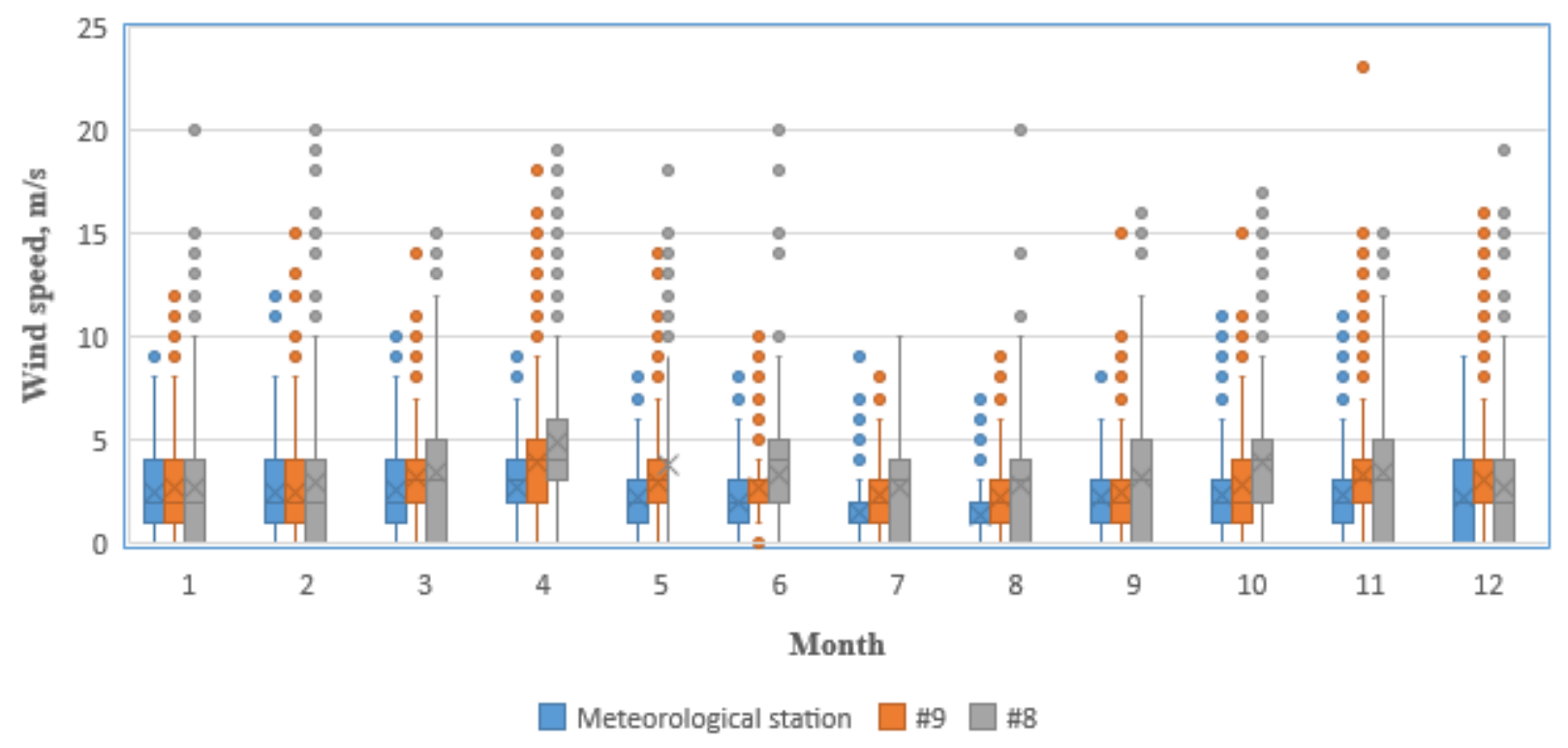

Fig. 15. Yearly average (during 1995-2005) of monthly wind speeds at points \#8 and \#9 and at the meteorological station. 


\section{Figure}

Click here to download Figure: Figure 16.docx

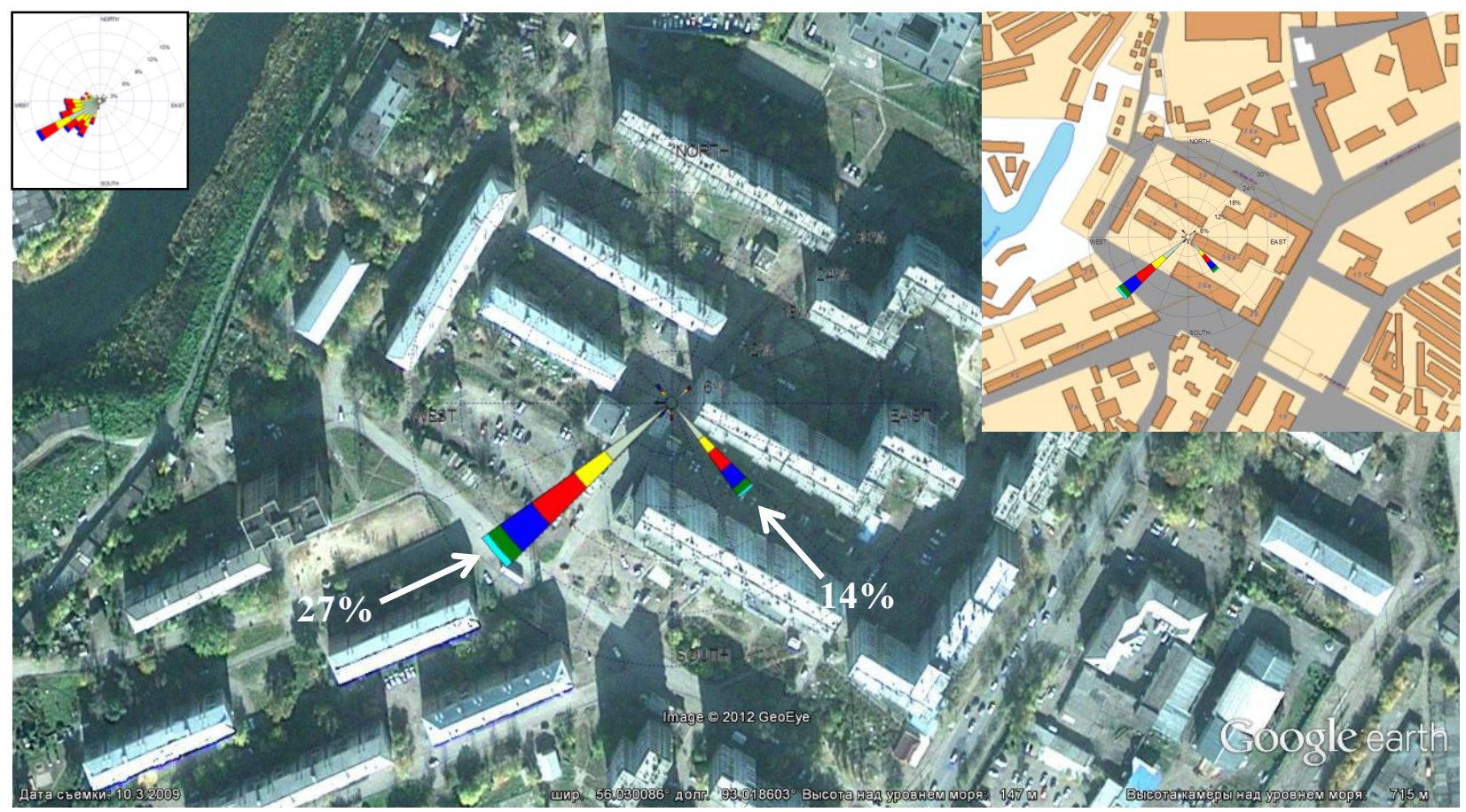

Fig. 16. Wind directions at point \#20 (wind frequencies are shown in percentages). At top left corner is the wind-rose for the meteorological station. The frequency of calms at point $\# 20$ is about $46 \%$. 
Figure
Click here to download Figure: Figure 17.docx

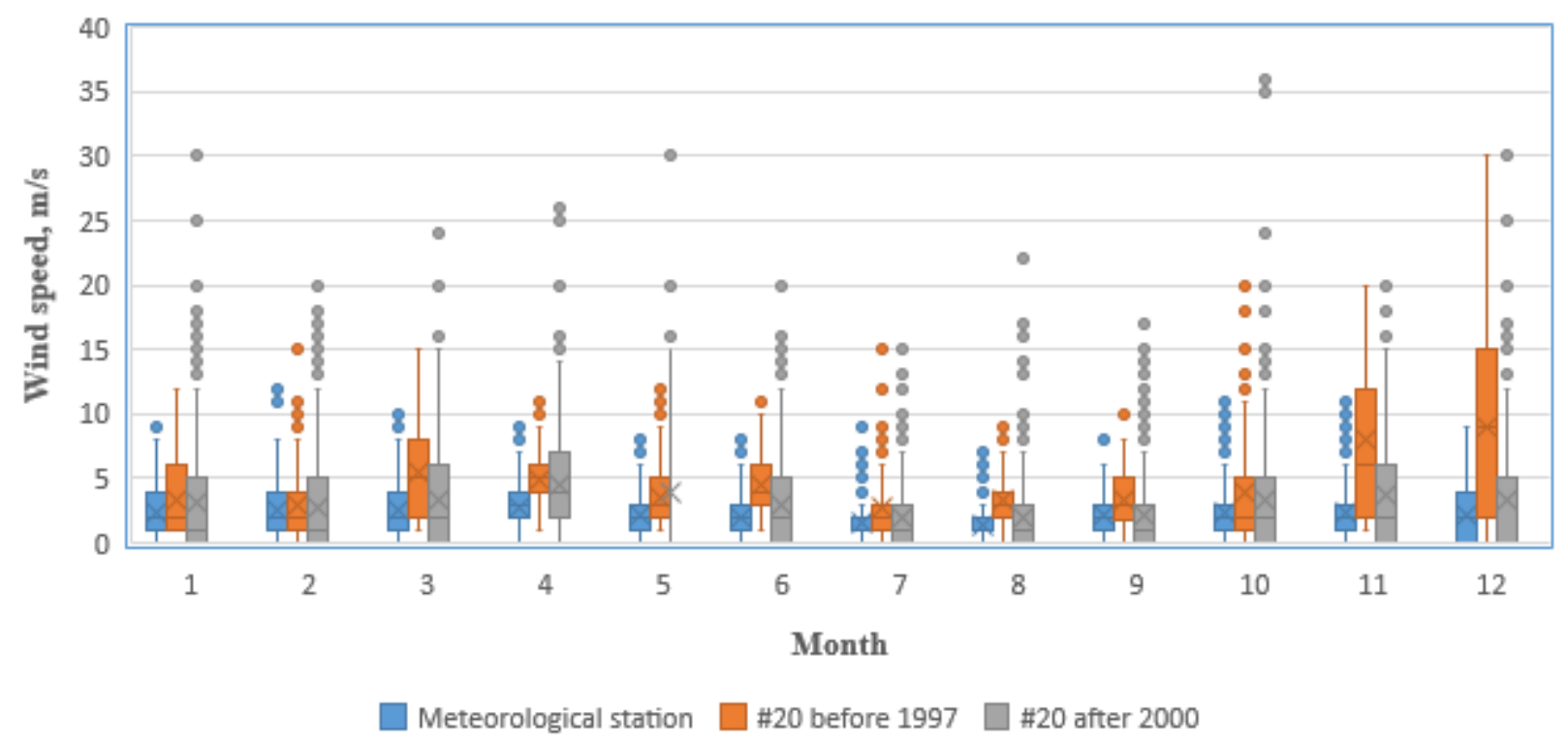

Fig. 17. Annual averages of monthly wind speeds at point \#20 (before 1997 and during 2001-2005) and at the meteorological station (during 1995-2005). 
Table 1

Features of transformation of wind streams in city

\begin{tabular}{|c|c|c|c|c|c|c|c|c|}
\hline Point & $\begin{array}{l}\text { Height, m } \\
\text { above sea } \\
\text { level }\end{array}$ & $\begin{array}{l}\text { Prevailing } \\
\text { winds }\end{array}$ & $\begin{array}{l}\text { Frequency, } \\
\%\end{array}$ & $\begin{array}{l}\text { Calms, } \\
\%\end{array}$ & $\begin{array}{l}\text { Building } \\
\text { height, m / } \\
\text { Building } \\
\text { density, \% }\end{array}$ & $\begin{array}{l}\text { Averaged } \\
\text { wind } \\
\text { speed, } \\
\mathbf{m} / \mathbf{s}\end{array}$ & $\begin{array}{l}\text { Wind } \\
\text { speed } \\
\text { varying, } \\
\text { m/s }\end{array}$ & $\begin{array}{l}\text { Correlation } \\
\text { coefficient } \\
\text { between wind } \\
\text { speeds at point } \\
\text { and at a } \\
\text { meteorological } \\
\text { station }\end{array}$ \\
\hline $\begin{array}{l}\text { Meteorological } \\
\text { station }\end{array}$ & 220 & $\begin{array}{l}200-280^{\circ}, \\
\text { Southwest + } \\
\text { West }\end{array}$ & 55 & 15 & $5 / 5$ & 2.3 & 0 & 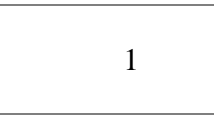 \\
\hline \#21 & 180 & $\begin{array}{l}45-55^{\circ}, \mathrm{NE} \\
135-145^{\circ}, \mathrm{SE}\end{array}$ & $\begin{array}{l}16 \\
12 \\
\end{array}$ & 60 & $15 / 20$ & 0.8 & -1.5 & 0.01 \\
\hline \#3 & 140 & $\begin{array}{l}225-235^{\circ}, \mathbf{S W} \\
270-280^{\circ}, \mathbf{W}\end{array}$ & $\begin{array}{l}25 \\
18 \\
\end{array}$ & 30 & $15 / 20$ & 1.4 & -0.9 & 0.72 \\
\hline \#5 & 200 & $\begin{array}{l}135-145^{\circ}, \mathrm{SE} \\
225-235^{\circ}, \mathrm{SW} \\
315-325^{\circ}, \mathrm{NW}\end{array}$ & $\begin{array}{l}14 \\
14 \\
41\end{array}$ & 18 & $30 / 10$ & 3.6 & +1.3 & 0.74 \\
\hline \#7 & 140 & $\begin{array}{l}45-55^{\circ}, \mathrm{NE} \\
135-145^{\circ}, \mathrm{SE} \\
225-235^{\circ}, \mathrm{SW}\end{array}$ & $\begin{array}{l}15 \\
20 \\
23\end{array}$ & 27 & $30 / 15$ & 1.2 & -1.1 & 0.86 \\
\hline$\# 8$ & 140 & $225-235^{\circ}, \mathbf{S W}$ & 50 & 30 & $15 / 15$ & 3.3 & +1.0 & 0.53 \\
\hline \#9 & 140 & $\begin{array}{l}355-365^{\circ}, \mathrm{N} \\
45-55^{\circ}, \mathrm{NE} \\
175-185^{\circ}, \mathrm{S} \\
225-235^{\circ}, \mathbf{S W} \\
265-275^{\circ}, \mathbf{W} \\
315-325^{\circ}, \mathrm{NW}\end{array}$ & $\begin{array}{c}11 \\
12 \\
6 \\
20 \\
24 \\
9 \\
\end{array}$ & 8 & $15 / 20$ & 2.8 & +0.5 & 0.76 \\
\hline \#20 & 140 & $\begin{array}{l}135-145^{\circ}, \mathrm{SE} \\
225-235^{\circ}, \mathrm{SW}\end{array}$ & $\begin{array}{l}14 \\
27\end{array}$ & 46 & $30 / 15$ & 3.1 & +0.8 & 0.85 \\
\hline
\end{tabular}

